\title{
Biogeographic responses and niche occupancy of microbial communities following long-term land-use change
}

Dennis Goss-Souza ( $\sim$ dennisgoss10@gmail.com )

Universidade do Estado de Santa Catarina Centro de Ciências Agroveterinárias https://orcid.org/00000003-3362-1789

\section{Siu Mui Tsai}

University of São Paulo

Jorge Luiz Mazza Rodrigues

University of California at Davis

Osmar Klauberg-Filho

Santa Catarina State University

José Paulo Sousa

University of Coimbra

Dilmar Baretta

Santa Catarina State University

Lucas William Mendes

University of São Paulo

\section{Research Article}

Keywords: Biodiversity hotspots, historical contingency, land-use change, microbial distance-decay, microbial niche specialization, soil bacterial co-occurrence

Posted Date: January 20th, 2022

DOI: https://doi.org/10.21203/rs.3.rs-1250532/v1

License: (c) (i) This work is licensed under a Creative Commons Attribution 4.0 International License.

Read Full License 
1 Biogeographic responses and niche occupancy of microbial communities

2 following long-term land-use change

3 Dennis Goss-Souza ${ }^{1,2,3^{*}}$, Siu Mui Tsai ${ }^{1}$, Jorge Luiz Mazza Rodrigues ${ }^{2,4}$, Osmar Klauberg-

$4 \quad$ Filho $^{3}$, José Paulo Sousa $^{5}$, Dilmar Baretta ${ }^{3,6}$, Lucas William Mendes ${ }^{1}$

$5{ }^{1}$ Center for Nuclear Energy in Agriculture, University of São Paulo, Piracicaba, SP, $6 \quad 13400-970$, Brazil

$7 \quad{ }^{2}$ Department of Land, Air and Water Resources, University of California at Davis, Davis, 8 CA 95616, USA

$9{ }^{3}$ Department of Soils and Natural Resources, Santa Catarina State University, Lages, SC 10 88523-000, Brazil. Current professional address

${ }^{4}$ Environmental Genomics and Systems Biology Division, Lawrence Berkeley National Laboratory, Berkeley, CA, 94720, USA

${ }^{5}$ Department of Life Sciences, University of Coimbra, Coimbra, Coimbra, P3000-456, Portugal.

${ }^{6}$ Department of Soils and Sustainability, Santa Catarina State University, Chapecó, SC, 89815-630, Brazil.

*Corresponding author: Santa Catarina State University - UDESC

Department of Soils and Natural Resources

Soil Ecology and Ecotoxicology Laboratory

Av. Luis de Camões, 2090

Lages, SC, 88523-000

Brazil

Phone: +55-49-3289-9233

E-mail: dennis.souza@udesc.br

Dennis Goss-Souza, http://orcid.org/0000-0003-3362-1789

Siu Mui Tsai, http://orcid.org/0000-0002-3733-6312

Jorge Luiz Mazza Rodrigues, http://orcid.org/0000-0002-6446-6462

Osmar Klauberg-Filho, http://orcid.org/0000-0002-7733-9745

José Paulo Sousa, http://orcid.org/0000-0001-8045-4296

Dilmar Baretta, http://orcid.org/0000-0001-8219-1362

Lucas William Mendes, http://orcid.org/0000-0003-0980-7006

Funding information. This study was funded by the São Paulo Research Foundation

(FAPESP/CNPq No. 2008/58114-3 and FAPESP/NSF No. 2014/50320-4) and by the

National Council for Scientific and Technological Development (SisBiota-CNPq No. 
563251/2010-7). DG-S received a scholarship from CNPq-FAPESP (PRONEXCNPq/FAPESP No. 140317/ 2014-7). DB thanks CNPq for his Research Productivity Grant (CNPq-PQ No. 305939/2018-1). SMT also thanks CNPq for her Research Productivity Grant (CNPq-PQ No. 311008/2016-0). LWM thanks FAPESP for his Young Researcher Grant (FAPESP No. 2020/12890-4 and 2019/16043-7). We thank all the staff of the SisBiota Thematic Project, for helping us in sampling campaigns and soil analyses.

Ethical statement. This article does not contain any studies with human participants and/or animals performed by any authors.

Consent to participate. Not applicable.

Consent for publication. Not applicable.

Data availability. All data generated or analyzed in this study are included in the article and its supplementary information files.

Conflict of interest. The authors declare that they have no conflict of interest.

Author contributions. DG-S, SMT, OK-F, JPS, and DB, designed the project. DG-S, OK-F, and DB collected the soil samples. DG-S and LWM performed molecular biology analyses. DG-S, LWM, and JLMR analyzed the data. All authors wrote, commented, and accepted the final version of the manuscript. 


\section{Abstract}

61 Understanding the effects of forest-to-agriculture conversion on microbial diversity has been a major goal in soil ecological studies. However, linking community assembly to the ruling ecological processes at local and regional scales remains challenging. Here, we evaluated bacterial community assembly patterns and the ecological processes governing niche specialization in a gradient of geography, seasonality, and land-use change, totalizing 324 soil samples, 43 habitat characteristics (abiotic factors), and 16 metabolic and co-occurrence patterns (biotic factors), in the Brazilian Atlantic Rainforest, a subtropical biome recognized as one the world's largest and most threatened hotspots of biodiversity. We observed no significant shifts in alpha diversity due to land-use change. Meanwhile, pairwise beta diversities and distance decays were lower in pastures than those observed for forest and no-till soils. Pasture communities showed a predominantly neutral model, regarding stochastic processes, with moderate dispersion, leading to biotic homogenization. Most no-till and forest microbial communities followed a niche-based model, with low rates of dispersal and weak homogenizing selection, indicating niche specialization or variable selection. Historical and evolutionary contingencies, as represented by soil type, season, and dispersal process were the main drivers of microbial assembly and processes at the local scale, markedly correlated with the occurrence of endemic microbes. Our results indicate that the patterns of assembly and their governing processes are dependent on the niche occupancy of the taxa evaluated (generalists or specialists). They are also more correlated with historical/evolutionary contingencies and the interactions among taxa (i.e. co-occurrence patterns) than the land-use change itself. Keywords: Biodiversity hotspots, historical contingency, land-use change, microbial distance-decay, microbial niche specialization, soil bacterial co-occurrence. 


\section{Introduction}

The Brazilian Atlantic Forest is the fourth world's richest hotspot of biodiversity, harboring $2.7 \%$ and $2.1 \%$ of the global endemic species of plants and vertebrates, respectively (Myers et al. 2000). However, in recent decades this biome has suffered from extensive fragmentation and destruction of forest canopies, with only $11.7 \%$ of the original vegetation remaining (Ribeiro et al. 2009). The conversion of forests to both croplands and pasturelands represents 20 and $42 \%$ of the total human net primary production (HNPP) appropriation in this biome (Weinzettel et al. 2018). By 2100, landuse change is expected to reduce natural vegetative cover by $26-58 \%$ in all 34 global hotspots of biodiversity, compared to 2005 (Jantz et al. 2015). The same study predicted that, by the end of the century, forest conversion to croplands and pasturelands could contribute up to $1 / 3$ of the habitat loss and up to $16 \%$ loss of plant and animal species in those hotspots due to land-use change only.

As with plants and animals, soil microorganisms are very responsive to land-use change (Lauber et al. 2013; Kaiser et al. 2016; Li et al. 2019; Ceola et al. 2021). Investigations of local microbial communities in the Amazon Forest Biome (Northwestern Brazil) have shown that the conversion of forest in pasturelands and croplands often leads to bacterial diversity loss (Jesus et al. 2009; Rodrigues et al. 2013; Mendes et al. 2015b; Goss-Souza et al. 2020) and affects ecosystem services related to the microbial activity (Paula et al. 2014; Meyer et al. 2017; Goss-Souza et al. 2019; Pedrinho et al. 2019). Most of the works listed above have described taxa trade-offs, diversity turnover, and shifts in microbial functions, resulting from land-use change, as dependent on local abiotic environmental filters (e.g. soil pH, soil organic matter, soil fertility), which is indicative of homogeneous selection process (Stegen et al. 2013). When looking to the Atlantic Forest, just a few works evaluated the diversity of soil 
bacterial communities in the subtropical region of this biome (Southern Brazil) (Faoro et al. 2010) and the consequences of forest-to-agriculture conversion for both bacterial diversity and ecological processes shaping bacterial distribution (Goss-Souza et al. 2017). The hypothesis of distance-decay relationship (DDR) of biodiversity, which infers about the decrease of taxa similarity (or increase in taxa dissimilarity) the extend the distance between pairwise microbial communities increase has been applied with success to solve this ecological gap (Horner-Devine et al. 2004; Martiny et al. 2011; Shade et al. 2018; Gao et al. 2019). Complementary to the DDR, the continuum hypothesis states that stochastic processes along with deterministic selection contribute to the assembly of ecological communities (Stegen et al. 2013; Dini-Andreote et al. 2015; Powell et al. 2015; Tripathi et al. 2018). DDRs have been linked with success with the ecological dispersal process (Martiny et al. 2011), which refers to the tendency to migrate by individuals from a local population or community, leading to homogenous dispersal, when rates of migration are high or, dispersal limitation, when the dispersal rates are low (Sengupta et al. 2019). The variation in microbial diversity related to random birth and death or spatial distance between sites, not related to environmental selection, indicates a drift process. Drift could act as the dominant process in microbial communities when overall population abundance and community diversities are low (Nemergut et al. 2013), leading to an increased risk of extinction (Cordovez et al. 2019). Moreover, dispersal and drift can act together as stochastic forces, leading to microbial neutral assembly (Cottenie 2005; Székely and Langenheder 2014; Goss-Souza et al. 2017, 2020).

The homogeneous selection is assumed to be a pivotal driver of local assembly dynamics of bacterial communities (e.g. in the same toposequence) (Jesus et al. 2009; Dini-Andreote et al. 2014; Mendes et al. 2015a). However, several studies have shown weak correlations between assembly and homogeneous environmental filtering in 
regional or continental scales (Feng et al. 2019; Gao et al. 2019). The explanation could reside in a complementary selection force, the variable selection process, which occurs when heterogeneous selective environments lead microbial communities to be overdispersed (e.g. increase in SOM quantity and/or quality, microbial cooperation and co-occurrence, microbial activity) (Dini-Andreote et al. 2015), with microbial communities modulated by intra- and interspecific biotic relationships among species, in detriment of environmental abiotic filters (Gao et al. 2019). To account for this, species association has been regularly used in microbial ecology to infer biotic interactions resulting from the variable selection process (Ferrenberg et al. 2013; Nemergut et al. 2013; Wang et al. 2020). Otherwise, just a few studies have used microbial networks for examining species association and variable selection in biogeographical studies (Ma et al. 2016; Gao et al. 2019). The outcome of network topological properties results in cooccurrence and co-exclusion patterns, which can offer valuable insights about biotic interactions within sets of microbial communities (Dini-Andreote et al. 2014; Jones and Hallin 2019), although some studies have argued that spatial associations between species is not a good proxy for ecological interactions (Blanchet et al. 2020). Microbial ecologists are now focusing on the hypothesis that, besides homogeneous selection, other ecological processes, such as variable selection, dispersal limitation, and drift are important drivers of the variability in assembly patterns along with geographic gradients (Hanson et al. 2012; Ranjard et al. 2013). However, a few studies have tested and quantified those complementary processes in biogeography studies (Fan et al. 2017; Feng et al. 2019; Gao et al. 2019).

As soil microbial communities are often very complex, most biogeography studies have described the distance decay patterns in terms of overall communities (Martiny et al. 2011; Ranjard et al. 2013; Rodrigues et al. 2013). However, a few recent studies have 
raised the hypothesis that the distance decay relationship and, consequently, the ecological processes governing assembly in bacterial communities could vary between habitat generalists and specialists (Gao et al. 2019; Luo et al. 2019). While generalists follow the Baas Becking theory of "everything is everywhere" (De Wit and Bouvier 2006), habitat specialists are the microorganisms that have restricted occupancy, as represented by their low occurrence across environmental and geographical gradients (Meyer et al. 2018; Gao et al. 2019; Ceola et al. 2021). The competitive/cooperative interactions among microbial populations in a local community (Li et al. 2018) and sets of metapopulations in metacommunity (Hovatter et al. 2011; Rocha et al. 2021) are very intricate (Leibold et al. 2004) and land-use change can greatly alter the role of these interactions in microbial community assembly (Creamer et al. 2016; Brinkmann et al. 2019; Goss-Souza et al. 2020). Some authors have found land-use change and management intensification in tropical soils, as selective abiotic filters, by increasing the competition among species for habitat and limiting resources, according to niche (Mendes et al. 2014; Goss-Souza et al. 2019). Linking the occurrence of those endemic and ubiquitous taxa with the environmental and geographical gradients could enable microbial ecologists to survey the consequences of human intervention on microbial diversity and habitat specialization. Furthermore, it will allow us to depict the possible relationships between aboveground plant habitat and diversity loss, due to deforestation and land-use change and the outcome for belowground soil microbial communities, with consequences for management and conservation strategies in this threatened biome.

Here, we investigated the distribution and DDR patterns of beta diversities and consequent ecological processes governing microbial assembly along with multiple spatial scales. Moreover, we linked those patterns and processes to habitat transformation, resulting from the long-term conversion of the Atlantic Forest into no-till cropping and 
pasture areas. Our central hypothesis affirmed that (i) the microbial assembly would vary along land uses, and geographic distance between microbial communities with a decrease in microbial diversity in the converted agriculture soils of local communities. We also hypothesized that (ii) the balance between neutral and niche-based assembly models would differ along land uses and spatial scales, being neutral in the forest soils, and local communities and niche-based in the agriculture soils and regional communities. A third hypothesis stated that (iii) the processes governing microbial assembly would vary from stochastic to deterministic between habitat generalists and specialists, respectively. By combining 16S rRNA T-RFLP fingerprint and a large set of abiotic (43 soil and landscape parameters) and biotic factors (16 metabolic and co-occurrence patterns) in a broad spatial scale $(0-378 \mathrm{~km})$, we aimed (i) to verify the changes in bacterial assembly patterns, (ii) to identify the features that impose assembly, and (iii) to underlie the ecological processes governing assembly across spatial scales for overall bacterial communities, generalists and specialists.

\section{Material and Methods}

\section{Study areas, soil sampling, and environmental analyses}

The sampling sites were located within the subtropical Atlantic Forest Biome, at Santa Catarina State, Brazil (Supplementary Fig. S1a), and represented (1) remnants of the original forest cover, and the long-term conversion of forest into (2) no-till cropping and (3) pasturelands. The forest sites comprised a natural transition between mixed ombrophilous forest and semi-deciduous forest, with a predominance of Araucaria angustifolia (fam. Araucariaceae) in the western mesoregion and Mimosa scabrella (Fabaceae) in the plateau mesoregion. Other frequent species in forest sites were Apuleia leiocarpa, Balfourodendron riedelianum, Cabralea glaberrima, Cedrela fissilis, Cordia 
trichotoma, Diatenopterix sorbifolia, Enterolobium contortisiliquum, Lonchocarpus leucanthus, Parapiptadenia rigida, Patagonula americana, and Peltophorum dubium. Forest areas were deforested via timber slash-and-burn and converted in two distinct land uses, in the late 1980s: i) No-till cropping systems, characterized by successive rotational cultivation of wheat, and eventually, oat and ryegrass in the winter, followed by soybean and maize in the summer, and; ii) Pasturelands, characterized by a mix of perennial grasses with a predominance of Axonopus affinis (Poaceae) in western mesoregion and Andropogon lateralis (Poaceae) in plateau mesoregion. The selection of sampling sites was based on land-use history and management, obtained from previous exploratory campaigns, interviewing farmers and experts. The main criterion of selection was the conversion of forest to no-till or pasture at least 10 years before sampling. Samples were collected in July and January, comprising winter and summer seasons of the southern hemisphere, respectively, in a gradient of latitude, longitude, and altitude. Sampling counties were São Miguel do Oeste (2644’S; 53³2’W; 652 meters above sea level masl), Chapecó $\left(27^{\circ} 3^{\prime} \mathrm{S} ; 5^{\circ} 40^{\prime} \mathrm{W} ; 642\right.$ masl) and Xanxerê $\left(26^{\circ} 50^{\prime} \mathrm{S} ; 52^{\circ} 28^{\prime} \mathrm{W} ; 728\right.$ masl) in the western mesoregion and, Campo Belo do Sul (2752'S; 50³9’ W; 978 masl),

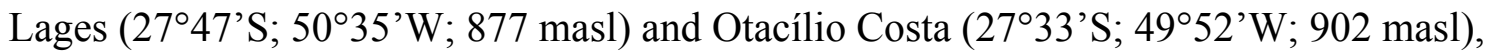
in the Plateau mesoregion, Santa Catarina State, Brazil (Supplementary Fig. S1a). The climate in both mesoregions is humid temperate mesothermal (Cfb) (Köppen classification), with no marked dry season and rainfalls equally distributed throughout the year. The historic mean annual temperature varies from $18-22^{\circ} \mathrm{C}$ in the western to 14 $18^{\circ} \mathrm{C}$ in the Plateau.

To evaluate microbial assembly patterns (response variables), non-deformed soil samples from the $0-10 \mathrm{~cm}$ profile were collected with sterile PVC tubes $(5 \mathrm{~cm}$ diameter $\times 10 \mathrm{~cm}$ depth), yielding $\sim 500 \mathrm{~g}$ of soil each. Each sample was collected in a $3 \times 3$ 
235 Cartesian square-geogrid scheme, equidistantly by $30 \mathrm{~m}$ from each other, with $20 \mathrm{~m}$ of

236 the border, totalizing an area of one hectare per sampling site (Supplementary Fig. S1b).

237 A total of 324 individual soil samples were collected $(9$ samples per geogrid $\times 3$ land uses

$238 \times 6$ counties $\times 2$ sampling seasons). Samples were kept on dry ice and transported to the

239 Cell and Molecular Biology Laboratory, Center for Nuclear Energy in Agriculture

240 (Piracicaba, Brazil), within 24 hours, to further molecular procedures. For soil physical,

241 chemical, and microbiological parameters, used as explanatory variables, samples were

242 collected at the same points (also totalizing 324 independent samples). Soil samples were maintained at $4{ }^{\circ} \mathrm{C}$ and transported to the Soil Analysis Laboratory, Santa Catarina State University (Lages, Brazil). The soil physical analyses performed were soil density, porosity (total-, macro-, micro- and bioporosity), texture, particle density, aggregate diameter, and penetration resistance. The chemical characteristics analyzed were soil $\mathrm{pH}$, total $\mathrm{C}, \mathrm{H}, \mathrm{N}$, and $\mathrm{S}, \mathrm{C}: \mathrm{N}$ ratio, soil organic matter, soil organic $\mathrm{C}, \mathrm{P}, \mathrm{K}, \mathrm{Al}, \mathrm{Ca}$, and $\mathrm{Mg}$. All the physical and chemical analyses were performed following routine methodology (Keeney and Nelson 1982; Gee and Bauder 1986; Dexter 1988; Cambardella and Elliott 1992; Tedesco et al. 1995; Claessen et al. 1997; Dexter et al. 2007; Dhaliwal et al. 2011; Teixeira et al. 2017). Microbiological metabolic analyses included soil microbial C, soil basal respiration, metabolic quotient, and microbial quotient, also performed through a routine methodology (Sparling and West 1988; Sparling 1992; Anderson and Domsch 1993; Alef and Nannipieri 1995). Soil types were classified using the World Reference

Base for Soil Resources (Anjos et al. 2015). Details about site management history, sampling, and environmental analyses are available as supporting information. See also (Bartz et al. 2014; Goss-Souza et al. 2017). 
260 To investigate bacterial diversity patterns and processes structuring bacterial 261 communities across land uses, seasons, and geographical distances, we used the T-RFLP 262 method. T-RFLP quantifies the variability in DNA sequences of genes or intergenic space regions (e.g. bacterial small subunit $16 \mathrm{~S}$ rRNA, fungal ITS), generating a DNA 'fingerprint' of unique fragments, with the size and abundance of each fragment in a soil sample. Although sequencing provides more detailed phylogenetic information, T-RFLP as an automated fingerprinting method is a simpler and less expensive system that allows the comparison of a high amount of soil samples (van Dorst et al. 2014), with sufficient replication to address soil microbial patterns of diversity and structure (Fierer and Jackson 2006; Dumbrell et al. 2010; Székely and Langenheder 2014; Lange et al. 2015; Kari et al. 2019). Also, T-RFLP generates results consistent with that found in high throughput sequencing (Vega-Avila et al. 2014; Powell et al. 2015; Durrer et al. 2017; Karczewski et al. 2017; De Vrieze et al. 2018). To accomplish that, total DNA extraction (250 mg) was performed for the 324 soil samples (See Supplementary Fig. S1), using PowerLyzer PowerSoil $^{\mathrm{TM}}$ DNA Isolation Kit (Mo Bio Laboratories, Carlsbad, USA). DNA quality was verified in gel electrophoresis with Tris-buffered saline with sodium boric acid and $1 \%$ agarose (Brody and Kern 2004). DNA concentration was measured with the Qubit ${ }^{\mathrm{TM}}$ 277 fluorometer (Thermo Fischer Scientific, Waltham, USA). T-RFLP fragments amplification was performed in a thermal cycler GeneAmp PCR System $9700^{\mathrm{TM}}$ (Thermo Fischer Scientific, Waltham, USA), using the 16S rRNA universal set of primers 27F (5' AGA GTT TGA TCC TGG CTC AG 3') labeled with 6-FAM (Edwards et al. 1989) and 1492R (5' GGT TAC CTT GTT ACG ACT T 3') (Turner et al. 1999). The PCR mix contained 10X Platinum Taq PCR buffer, $3.0 \mathrm{mM} \mathrm{MgCl}_{2}, 0.2 \mathrm{mM}$ of each dNTP, $0.5 \mathrm{mM}$ of each primer and $0.05 \mathrm{U}_{\mu} \mathrm{L}^{-1}$ of Platinum ${ }^{\mathrm{TM}}$ Taq DNA polymerase (Thermo Fischer 
optimize the reaction. Reaction consisted in a pre-denaturation step at $94^{\circ} \mathrm{C}$ for 3 minutes, followed by 35 cycles of $94^{\circ} \mathrm{C}$ for 30 seconds, $59^{\circ} \mathrm{C}$ for 45 seconds, and $72^{\circ} \mathrm{C}$ for 60 seconds, with a final extension of $72^{\circ} \mathrm{C}$ for 15 minutes. Reaction products were then purified using GFX ${ }^{\mathrm{TM}}$ PCR DNA and Gel Band Purification Kit (GE Health Care, Chicago, USA), according to the manufacturer's instructions. Ten to 60 nanograms of the amplified and purified DNA were used in $10 \mu \mathrm{l}$ of restriction reaction using HhaI endonuclease (Thermo Fischer Scientific, Waltham, USA), at $37^{\circ} \mathrm{C}$ for 3 hours. Digested DNA was then purified using $60 \mu 1$ of absolute ethanol with $2 \mu 1$ of sodium acetate/EDTA $(100: 1 ; 0.1 \%)$ and centrifuged at $4000 \times g$ for 45 minutes, followed by another step, adding $150 \mu \mathrm{l}$ of absolute ethanol/water (7:3) and centrifuging at $4000 \times g$ for 45 minutes. The purified DNA pellet was eluted in $9.8 \mu \mathrm{l}$ of deionized formamide with $0.2 \mu \mathrm{l}$ of GeneScan-500 ROX ${ }^{\mathrm{TM}}$ internal size standard (Thermo Fischer Scientific, Waltham, USA). The product was denatured at $94^{\circ} \mathrm{C}$ for 5 minutes in a thermal cycler GeneAmp PCR System $9700^{\mathrm{TM}}$ (Thermo Fischer Scientific, Waltham, USA). Fragments were analyzed in an ABI Prism $3100^{\mathrm{TM}}$ automated sequencer (Thermo Fischer Scientific, Waltham, USA) following the manufacturer's instructions. The size and the intensity of each terminal restriction fragment were estimated using GeneMapper version 3.0 (Thermo Fischer Scientific, Waltham, USA) and are hereafter described in terms of operational taxonomic units (OTUs) (Schütte et al. 2008; Rodríguez-Valdecantos et al. 2017). Only fragments ranging from 50 to $500 \mathrm{bp}$ were analyzed.

\section{Microbial profiling and assembly patterns}

We first calculated the overall Chao-1 estimated richness and Shannon's alpha diversity for each land use and season. Means were compared through ANOVA with Tukey's Honest Significant Difference test (Tukey's HSD), with the function 'tukeyHSD', on R 
software, version 4.0.2 (R Core Team, 2020). To evaluate the overall distribution of beta diversities, we performed a multivariate Principal Coordinates Analysis (PCoA), with Monte-Carlo permutations on Canoco software, version 5.2 (Lepš and Šmilauer 2005). From the resulting Bray-Curtis distance matrix, we measured the clustering of beta diversities resulting from $\mathrm{PCoA}$ ordination, through non-parametric Permutational Analysis of Variance (PERMANOVA), as implemented by 'adonis' function in 'vegan' package, version 2.5-6 (Anderson 2001; Oksanen et al. 2019), on R software. AdonisPERMANOVA allowed us to test whether beta diversities were separated by land use, season, and geographic location. Then, we calculated the distributions of observed beta Sørensen pairwise dissimilarities, using the function 'beta.pair' in 'betapart' R package, version 1.5.1 (Baselga et al. 2018). We partitioned the values Sørensen pairwise beta diversities $\left(\mathrm{B}_{\mathrm{SOR}}\right)$ into the turnover $\left(\mathrm{B}_{\mathrm{SIM}}\right)$ and the nestedness $\left(\mathrm{B}_{\mathrm{SNE}}\right)$ components of diversity. We found that the turnover component dominated the partitioning for all landuses and seasons (Supplementary Fig. S2). Moreover, using Sørensen's presence/absence matrices and analyzing samples from a large geographic scale $(0-378 \mathrm{~km})$ in the same dataset, pairwise comparisons almost reached the limit of the signal of the Sørensen index $\left(\mathrm{B}_{\mathrm{SOR}}=1\right)$ for all land uses and seasons. Thus, we decided to depict the variation in diversification through pairwise Bray-Curtis abundance-based dissimilarities, across land uses and seasons, using the function 'beta.multi.abund' (Baselga 2017), also in the 'betapart' R package. We performed the Shapiro-Wilk W test for normal probability, using the function 'shapiro.test' on R. Data presented non-parametric distribution, hence we used the Kruskal-Wallis (chi-square) non-parametric test, with corrected P-values to compare the means of beta diversities across land uses and seasons, using the function 'kruskal.test' on R. 
336 To obtain a signal of microbial ecological interactions modulating assembly complexity

337 patterns, we performed non-random co-occurrence network analysis, using the Python 'SparCC' tool, which estimates correlation values from compositional data (Friedman and Alm 2012). First, we calculated SparCC co-occurrence metrics for overall communities, according to land use and season $(54$ samples $\times 3$ land uses $\times 2$ seasons $=$ 324 samples). Complementary, pairwise microbial communities were compiled in local and regional communities, within and over the mesoregion threshold, respectively, according to spatial distance. Local and regional communities were defined by complementary analyses of Moran's I test for spatial autocorrelation and 3D spatial interpolation through the gridding semivariogram method, with Jackknife cross-validate permutations. After defining the limit distance for autocorrelation, we calculated SparCC co-occurrence metrics for local communities, which is the set of pairwise communities within Moran's threshold for autocorrelation and regional communities, regarded as the pairs of microbial communities over the limit for autocorrelation. For each network (overall, local or regional), P-values were obtained by 100 random permutations for each set of samples. Only OTUs with SparCC significant $(\mathrm{P}<0.01)$ and correlations with a magnitude of SparCC $>0.6$ or $<-0.6$ were included into the network analyses. The nodes in the reconstructed networks represented the OTUs, while the edges represented significant positive or negative correlations between nodes. Co-occurrence patterns were calculated in the interactive platform Gephi, version 0.9.2 (Bastian et al. 2009), and network graphs were built with the 'Fruchterman Reingold' design. The metrics evaluated were average node connectivity, average path length, cumulative degree distribution, network diameter modularity, number of edges, number of nodes, and number of communities. The resulting values of those metrics were used as biotic factors, 
representing the variable selection process, on further multivariate partitioning analyses. From the resulting networks, we were also able to extract the major hub taxa, represented by the set of OTUs with the highest betweenness centrality, which measures the extent to which a node lies on paths between other nodes.

To test the turnover of microbial abundances across land uses and seasons, we performed the Multinomial Species Classification Method (CLAM test) (Chazdon et al. 2011), classifying all the possible phylotypes (275 OTUs) according to their habitat specialization, as generalists and specialists, using the 'clamtest' function, in 'vegan' $\mathrm{R}$ package, according to the estimated species relative abundance. The test was applied using the supermajority rule $(\mathrm{K}=2 / 3, \mathrm{P}<0.005)$. After that, we were able to investigate whether the hub OTUs in each network were generalists or specialists.

\section{Distance-decay patterns of beta diversities}

To assess the geographic scale dependence of microbial community diversities, we performed distance-decay relationship (DDR) models of beta pairwise Bray-Curtis dissimilarities, ranging from 0.03 to $378 \mathrm{~km}$ (See map, Supplementary Fig. S1a), using the function 'decay.model', in the 'vegan' R package (Nekola and Mcgill 2014; GómezRodríguez and Baselga 2018). The best-fitted GLM model was chosen according to the lowest Akaike Information Criterion (AIC) value (Gómez-Rodríguez and Baselga 2018) and the highest pseudo- $\mathrm{R}^{2}$ value (Robeson et al. 2011). After choosing the best-fitted model, we used the slope (the rate at which dissimilarity increases with distance), associated with a p-value, to infer the significance of the best-fitted decay model.

\section{Assembly models, selection, and dispersal}


384 To investigate the species association patterns across land uses and seasons, we calculated species rank abundance distributions (RADs) for each of the 324 samples and fitted them to four different theoretical assembly models: the zero-sum multinomial (ZSM) and the broken stick (null model), which regard to neutral assembly, and; the pre-emption and the log-normal, related to a niche-based assembly. Broken stick, pre-emption and, log-normal models were calculated using the 'radfit' function from the 'vegan' R package. The ZSM model was calculated on TeTame software, version 2.16 (Jabot et al. 2008). The models were compared based on the AIC. The lowest AIC value, the best-fitted model for each sample (Bozdogan 1987). The dispersal rates, related to the tendency to migrate from members of a certain community, were calculated for each sample, through Etienne's formula (Etienne and Alonso 2005), on TeTame.

From the Bray-Curtis dissimilarity matrices, we calculated beta-diversity distributions for local and regional communities with the function 'vegdist' on the 'vegan' R package (Oksanen et al. 2019). Then, we performed permutations resemblance of those Bray-Curtis dissimilarity distance distributions under the null model with the function 'swap_count' from the 'vegan' R package. Afterward, we generated the Z-scores for the set of microbial communities with the function 'oecsimu' (Ulrich and Gotelli 2010), also from the 'vegan' R Package. The Z-score refers to the deviation of expected Bray-Curtis pairwise distributions under permutations to the observed value, indicating the distance of a certain set of pairwise beta diversities from the null expectation (Keil 2019). Pairwise diversities with Z-score $<-2$ reflected aggregation, which means that OTUs co-occurred more than expected by the null model, while pairwise diversities with Z-score $>+2$ reflected segregation, meaning that OTUs co-occurred less than expected by the null model (Dini-Andreote et al. 2015; Gao et al. 2019). We considered the co-occurrence patterns of microbial communities as non-random, resulting from deterministic 
homogeneous $(Z$-score $<-2)$ or variable selection $(Z$-score $>+2)$ processes, while Zscores within those values $(-2<Z$-score $<+2)$, indicated that communities co-occurred randomly, governed by drift and/or dispersal stochastic processes.

\section{Variation partitioning of factors modulating assembly of microbial communities}

To investigate the importance of geographic coordinates as primary predictors of BrayCurtis dissimilarities across spatial scales, we first performed a Principal Coordinates Analysis of Neighbor Matrices (PCNM), with forward-selection, setting Latitude, longitude, and altitude as primary predictors and the resulting coordinates (PCNM axes) as spatial predictors. Latitude and longitude were used as constraining variables in the model. From the resulting PCNM non-collinear and significant variables (Bonferroni correction), we depicted the proportion of the variation in the microbial assembly of overall bacterial communities, generalists and, specialists explained by (1) geography, (2) abiotic factors, and (3) biotic factors, via Mantel and partial Mantel tests, with Pearson correlations, according to geographic distance, with the functions 'mantel' and 'partial.mantel' (Legendre and Fortin 1989), in the 'vegan' R Package.

\section{Results}

\section{Profiling of microbial communities}

Chao-1 Richness and Shannon's $\alpha$-diversity $\left(H^{\prime}\right)$ among land uses and seasons were compared through Tukey's HSD test (Supplementary Fig. S3). Richness of OTUs did not vary across land uses in winter season $\left(\mathrm{P}_{\text {same }}=0.414\right)$. Otherwise, we found differences in richness for summer $\left(\mathrm{P}_{\text {same }}=0.018\right)$, with no-till $($ Chao- $1=92.3 \pm 21.7)$ richer than pasture $($ Chao- $1=79.1 \pm 27.8)(\mathrm{P}=0.027)$, and no differences between forest $($ Chao- $1=$ $80.5 \pm 28.9)$ and no-till $(\mathrm{P}=0.055)$ or forest and pasture $(\mathrm{P}=0.960)$. When comparing 
seasons within the same land use, we found no differences between winter and summer richness for forest $(\mathrm{P}=0.175)$ and pasture $(\mathrm{P}=0.892)$, with samples from no-till summer $($ Chao- $1=92.3 \pm 21.7)$ richer than winter $($ Chao- $1=80.0 \pm 30.7 ; \mathrm{P}=0.018)$. The same patterns were observed for $\alpha$-diversity, which did not vary across land uses in the winter $\left(\mathrm{P}_{\text {same }}=0.540\right)$ and varied across land uses in summer $\left(\mathrm{P}_{\text {same }}<0.001\right)$. Depicting the variability in summer, no-till presented higher $\alpha$-diversity $\left(H^{\prime}=3.8 \pm 0.4\right)$ when compared to both forest $\left(H^{\prime}=3.5 \pm 0.4 ; \mathrm{P}=0.004\right)$ and pasture $\left(H^{\prime}=3.2 \pm 0.4 ; \mathrm{P}<0.001\right)$, with forest $\alpha$-diversity higher than pasture $(\mathrm{P}<0.001)$. Comparing seasons within the same land use, we found no differences between winter and summer $\alpha$-diversity for forest $(P=0.250)$ and pasture $(\mathrm{P}=0.114)$, with samples from no-till summer $\left(H^{\prime}=3.8 \pm 0.4\right)$ more diverse than winter $\left(H^{\prime}=3.4 \pm 0.7 ; \mathrm{P}=0.003\right)$.

\section{Beta diversity structures and distributions}

We investigated the beta diversity structure among land uses, through PCoA. The plot based on Bray-Curtis distances showed differences in structures of no-till microbial communities with both forest and pasture communities. Otherwise, forest and pasture communities presented a high degree of overlapping (Fig. 1). Variation in Bray-Curtis distances explained in the first two axes of PCoA was $34.78 \%$. Depicting the clustering of beta diversities resulting from principal coordinates ordination we found differences among land uses (PERMANOVA, Pseudo-F = 4.65, $\mathrm{P}=0.008$ ), seasons (Pseudo-F = $7.51, P=0.007)$ and sampling sites, represented by the six different counties (Pseudo-F $=12.08, \mathrm{P}<0.001)$. Thus, to explore the first two significant correlations from PERMANOVA, we depicted the variation in beta pairwise diversities distributions, according to land use and season (Fig. 2). No differences in mean Bray-Curtis beta pairwise diversities were found in winter season, resulting long-term forest $\left(\beta_{\mathrm{BC}}=0.58\right)$ 
459 conversion to no-till $\left(\beta_{\mathrm{BC}}=0.57\right)\left(\right.$ Kruskal-Wallis test, $\left.\chi^{2}=3.6, \mathrm{P}_{\mathrm{FDR}}=0.226\right)$ or forest

460

461

462

463

464

465

466

467

468

469

470

471

472

473

474

475

476

477

478

479

480

481

482

conversion to pasture $\left(\beta_{\mathrm{BC}}=0.57\right)\left(\chi^{2}=3.6, \mathrm{P}_{\mathrm{FDR}}=1\right)$, with also no differences between no-till and pasture $\left(\chi^{2}=3.6, \mathrm{P}_{\mathrm{FDR}}=0.440\right)$. Yet for summer, mean pairwise beta diversities decreased after long-term forest $\left(\beta_{\mathrm{BC}}=0.59\right)$ conversion of forest to both no-till $\left(\beta_{\mathrm{BC}}=\right.$ 0.50) (Kruskal-Wallis test, $\left.\chi^{2}=232.7, \mathrm{P}_{\mathrm{FDR}}<0.001\right)$ and pasture $\left(\beta_{\mathrm{BC}}=0.52\right)\left(\chi^{2}=232.7\right.$, $\left.\mathrm{P}_{\mathrm{FDR}}<0.001\right)$, with diversities in pasture slightly higher than in no-till $\left(\chi^{2}=232.7, \mathrm{P}_{\mathrm{FDR}}\right.$ $=0.034)$. When looking for seasonal variation within land uses, we found no differences in beta diversities in forest $\left(\chi^{2}=2.5, \mathrm{P}_{\mathrm{FDR}}=0.118\right)$, with decreases from winter to summer in no-till $\left(\chi^{2}=154.2, \mathrm{P}_{\mathrm{FDR}}<0.001\right)$ and pasture $\left(\chi^{2}=55.1, \mathrm{P}_{\mathrm{FDR}}<0.001\right)$.

\section{Microbial co-occurrence patterns}

Overall, network complexity increased after forest conversion to both no-till and pasture and decreased from winter to summer, for both land uses (Fig. 3). Pasture communities presented the highest number of microbial OTUs with at least one significant $(\mathrm{P}<0.01)$ and strong correlation (SparCC $>0.6$ or $<-0.6$ ), as represented by the number of nodes in both seasons (Table 1). Pasture also showed the highest number of both positive and negative correlations among pairs of OTUs, the highest modularity, the larger network diameter, the larger average path length, and the larger average degree, in both seasons. The number of nodes, the number of edges, the number of positive and negative connections, network diameter, and average path length decreased from winter to summer in all land uses. The number of microbial communities did not vary between seasons for forest but increased in no-till and decreased in pasture, from winter to summer. The average degree decreased from winter to summer for forest and no-till and did not vary for pasture between seasons. 

land uses and seasons, according to their habitat specialization, as generalists and specialists (Fig. 4). From a total of 275 OTUs, we found 165 as generalists (60\%), 51 specialists in the plateau mesoregion (18.5\%), and 59 specialists in the western mesoregion (21.5\%). Investigating the seasonal OTUs turnover, in forest (Supplementary Fig. S4a), we found 160 generalists $(62 \%), 48$ specialists in winter (19\%), and 48 specialists in summer (19\%), of which 27 exclusives for forest winter and 11 exclusives for summer. In no-till (Supplementary Fig. S4c), we found 152 generalists (56\%), 59 specialists in winter (22\%), and 60 specialists in summer $(22 \%)$, being 25 exclusive for no-till winter and 21 exclusives for summer. In pasture (Supplementary Fig. S4e), we found 139 generalists (54\%), 79 specialists in winter (31\%), and 40 specialists in summer (15\%), of which 36 exclusives for pasture winter and 9 exclusives for summer. We also compared abundance turnover due to land-use change. In long-term forest-to-no-till conversion (Supplementary Fig. S4b), we found 139 generalists (52\%), 63 specialists in forest (23\%), and 68 specialists in no-till (25\%), with 20 exclusive for forest and 14 exclusives for no-till. Yet in long-term forest-to-pasture conversion (Supplementary Fig. S4d), we found 159 generalists (59\%), 69 specialists in forest (26\%), and 40 specialists in pasture (15\%), of which 10 were exclusive for forest and 12 exclusive for pasture. When comparing the differences in assemblages resulting from long-term land-use change (no-till vs. pasture; Supplementary Fig. S4f), we found 149 generalists (55\%), 69 specialists in no-till (26\%), and 52 specialists in pasture (19\%), with 12 exclusives for no-till and 20 exclusives for pasture.

We also sought for potential keystone taxa, the OTUs that hold the networks, as represented by high levels of betweenness centrality — the number of times a node plays a role as a connector between two other nodes, considered an important ecological and 
508 biological feature within a network (Supplementary Table ST2). We found three keystone 509 taxa in forest winter, with no evidence for the presence of keystone OTUs in forest 510 summer. The same as found for no-till, which had three keystone taxa for winter, with no

511 keystone taxa in summer. Yet for pasture, several OTUs seem to be keystone holders in 512 the networks of both winter and summer. When classifying the 20 most important 513 keystone taxa holding each network (Supplementary Table ST2), in terms of habitat 514 specialization, we found: 1) Forest winter: nine out of 20 seasonal specialists and six out 515 of 20 specialists in forest; 2) Forest summer: five out of 20 seasonal specialists and three 516 out of 20 specialists in forest; 3) No-till winter: seven out of 20 seasonal specialists and 517 eight out of 20 specialists in no-till; 4) No-till summer: four out of 20 seasonal specialists 518 and five out of 20 specialists in no-till; 5) Pasture winter: eight out of 20 seasonal specialists and six out of 20 specialists in pasture, and; 6) Pasture summer: three out of 20 seasonal specialists and four out of 20 specialists in pasture.

\section{Distance-decay patterns of beta diversities}

523 To investigate the third significant correlation from PERMANOVA analysis (that is geographic location), we evaluated the DDR patterns of beta pairwise diversities, for bacterial communities and also for generalists and specialists (Fig. 5). Geographical distances between pairs of microbial communities ranged from 0.03 to $397 \mathrm{~km}$. Linear and exponential slopes were significant $(\mathrm{P}<0.001)$ for overall bacterial communities (Fig. 5a), generalists (Fig. 5b), and specialists (Fig. 5c), evidencing increases in pairwise

529 Bray-Curtis dissimilarities the extend the distances between pairs of microbial 530 communities increased. We also depicted the variation in distance decay patterns for all land uses and seasons (Supplementary Fig. S5). In winter, we found no differences in 532 linear DDR slopes resulting from long-term conversion of forest (0.046) to no-till (0.048) 
or pasture (0.046). In summer, the linear slope increased after the long-term conversion of forest $(0.045)$ to pasture $(0.055)$ and decreased after conversion to no-till $(0.038)$. Comparing seasons, linear slopes of forest did not differ. Yet linear slope for no-till decreased from winter (0.048) to summer (0.038) and the opposite was found for pasture, where the slope increased from winter (0.046) to summer (0.055). Exponential slope patterns were similar to those found for linear slopes. In winter, we found no differences resulting from the long-term conversion of forest $(8.75 \mathrm{E}-07)$ to pasture $(8.83 \mathrm{E}-07)$, with an increased slope from forest to no-till (9.86E-06). In summer, exponential slopes were similar after long-term conversion of forest (1.09E-06) to pasture (1.05E-06) and decreased after conversion to no-till (8.75E-07). Comparing seasons, the exponential slope of forest increased from winter (8.75E-07) to summer (1.09E-06), the same as for pasture, where the exponential slope varied from 8.83E-07 to 1.05E-06. Yet exponential slope for no-till decreased from winter (9.86E-06) to summer (8.75E-07).

\section{Microbial assembly models across land uses and spatial scales}

We fitted all the 324 individual samples to theoretical ecological models, according to AIC. From the four tested models, microbial communities fitted predominantly to ZSM neutral model or lognormal niche-based model, with exception of one sample in pasture summer that fitted the preemption niche-based model (Fig. 6a). Most of the samples in forest (61.1\%) and no-till (63.9\%) fitted the niche-based lognormal distribution, which indicates the prevalence of deterministic processes governing microbial assembly. Otherwise, most of the samples in pasture fitted the ZSM neutral distribution (63.0\%), which regards stochastic processes governing assembly. When depicting the seasonal variation in assembly, we found an increase in the number of microbial communities fitting the neutral ZSM assembly from winter to summer, in both forest (35.2 to $42.6 \%$ ) 
and pasture (53.7 to $72.2 \%$ ). Differently, we observed a decrease in the number of microbial communities fitting the ZSM model from winter (44.5\%) to summer $(27.8 \%)$ in no-till. When comparing the dispersal rates across land uses and seasons (Fig. 6b), through the Kruskal-Wallis test, we observed an increase in the rates of dispersal resulting from the long-term conversion of forest to pasture in both winter (forest, $m=0.082$; pasture, $\left.m=0.143 ; \chi^{2}=51.0, \mathrm{P}_{\mathrm{Bonferromi}}>0.001\right)$ and summer $(($ forest, $m=0.092$; pasture, $\left.m=0.147 ; \chi^{2}=51.0, \mathrm{P}_{\text {Bonferromi }}>0.001\right)$, with no differences observed for the forest to no-till conversion, in both seasons, meaning more predisposition to migration from members of pasture local communities, compared with those from forest and no-till. We observed no seasonal effect on dispersal rates for any of the land uses.

When evaluating the influence of geographic distance in assembly patterns, we observed that beta pairwise diversities were lower in local scale-defined as the set of samples within the autocorrelation limit $(<97.196 \mathrm{~km}$; Supplementary Fig. S6)-compared to the regional scale (>97.196 km) (Figs. 7a and 7b), corroborating the significant DDR observed previously (Fig. 5a). We also found no differences across land uses in winter for both local and regional scales, as observed for overall diversities (See Fig. 2). Diversities decreased in summer on a local scale as a result of the conversion of forest to both no-till and pasture (Fig. 7a), with no significant differences observed at the regional scale, except for no-till, in which beta diversities decreased regionally from winter to summer (Fig. 7b). Comparing diversities within each land use, we found no differences for forest along seasons for local and regional scales. Yet for no-till, diversities decreased in summer in both local and geographic scales. For pasture samples, we noticed that diversities did not differ along seasons in geographic scales, although diversities decreased from winter to summer on a local scale. Thus, we investigated cooccurrence patterns of bacterial OTUs, through Z-scores (Keil, 2019), comparing the 
583

584

585

586

587

588

589

590

591

592

593

594

595

596

597

598

599

600

601

602

603

604

605

606

607

observed beta diversities across scales (Figs. 7a and 7b, dark bars), within each land use and season, with the expected diversity resulting from 10000 simulations under the null model (Figs. 7a and 7b, light bars). The resulting Z-score distributions after simulations are presented (Figs. 7c and 7d). At the local scale (Fig. 7c), Z-scores of most forest microbial communities, in winter and summer, fitted the null expectation, the same as for pasture communities, evidencing a neutral assembly, which is expected to occur when selection is weak, and assembly is governed by drift and dispersal processes. Yet for notill, in both seasons, most of the local communities fitted above the null expectation. Thus, local microbial communities in this environment are more segregated than expected by the null model, which is likely to occur when the variable selection process is acting. At the regional scale (Fig. 7d), Z-scores of forest microbial communities in winter and summer fitted above the null expectation, indicating segregation of communities across geographic distances. A similar trend was found for no-till, where the mean Z-scores were above the null expectation, regarding segregation, but with several communities fitting the null model, neutral. Geographic Z-scores of pasture communities presented the same trends as found for local communities, with most of the communities fitting the null model, in both seasons.

\section{Underlying the drivers of microbial community assembly across spatial scales and} niche occupancies

To evaluate the role of each set of variables (geography + abiotic + biotic) in structuring generalists and specialists decay profiles, we performed Mantel and Partial Mantel tests (Table 2). Mantel tests have shown that the variation in overall bacterial community dissimilarities, considering all land uses together (overall data) was mainly correlated with the biotic factors (Mantel, $\rho=0.292, P=0.001$ ), even after controlling for the effect 
608

609

610

611

612

613

614

615

616

617

618

619

620

621

622

623

624

625

626

627

628

629

630

631

632

of geographic distance (Partial Mantel, $\rho=0.278, P=0.001$ ) and abiotic factors (PM, $\rho$ $=0.277, P=0.001)$. Significant correlations were also observed with geographic distance $(\mathrm{M}, \rho=0.172, P=0.001)$ and to a lesser extent with abiotic factors $(\mathrm{M}, \rho=0.135, P=$ 0.001). For generalists, the variation was also correlated strongly correlated with the biotic factors $(\mathrm{M}, \rho=0.253, P=0.001)$, even after controlling for geographic distance (PM, $\rho=0.240, P=0.001)$ and abiotic factors (PM, $\rho=0.242, P=0.001)$. Significant correlations were also observed with geographic distance $(\mathrm{M}, \rho=0.172, P=0.001)$, with a minor effect of both geographic distance $(\mathrm{M}, \rho=0.157, P=0.001)$, and abiotic factors (M, $\rho=0.096, P=0.001)$. When looking for the specialists' correlations, the biotic factors $(\mathrm{M}, \rho=0.253, P=0.001)$ were again the major constraints of dissimilarities distributions, even after controlling for the effect of geographic distance and abiotic factors $(\mathrm{M}, \rho=$ $0.269, P=0.001$; in both cases). Significant correlations were also observed with abiotic $(\mathrm{M}, \rho=0.191, P=0.001)$, with a minor effect of geographic distance $(\mathrm{M}, \rho=0.160, P=$ $0.001)$

As we found signals of DDR for both exponential and power-law models (Fig. 5) and also differences in pairwise beta diversities for local and regional scales (Fig. 7), we sought for the evidence of differential patterns of correlations within and over the Moran's I autocorrelation threshold (See supplementary Fig. S6). To achieve that, we divided bacterial, generalists and, specialists dissimilarity matrices according to distance, in local (from 0 to $97.196 \mathrm{~km}$ ) and regional communities (>97.196 to $378.160 \mathrm{~km}$ ). At local scale, the variation in overall bacterial community dissimilarities was mainly correlated with the biotic factors (Table 2) $(\mathrm{M}, \rho=0.340, P=0.001)$, even after controlling for the effect of geographic distance (Partial Mantel, $\rho=0.299, P=0.001$ ) and abiotic factors (PM, $\rho$ $=0.309, P=0.001)$. Strong and significant correlations were also observed with geographic distance $(\mathrm{M}, \rho=0.308, P=0.001)$, even controlling for abiotic (PM, $\rho=$ 
633

634

635

636

637

$0.297, P=0.001)$ and biotic factors $(\mathrm{PM}, \rho=0.260, P=0.001)$ and to a lesser extent with abiotic factors $(\mathrm{M}, \rho=0.247, P=0.001)$, even controlling for geographic distance (PM, $\rho=0.233, P=0.001)$, and biotic factors (PM, $\rho=0.198, P=0.001)$. For generalists, the local variation was also strongly correlated with the biotic factors $(\mathrm{M}, \rho=0.299, P=$ $0.001)$, even after controlling for geographic distance (PM, $\rho=0.258, P=0.001)$ and abiotic factors $(\mathrm{PM}, \rho=0.277, P=0.001)$. Strong and significant correlations were also observed with geographic distance $(\mathrm{M}, \rho=0.285, P=0.001)$, even after controlling for biotic distance $(\mathrm{PM}, \rho=0.241, P=0.001)$ and abiotic factors distance $(\mathrm{PM}, \rho=0.276, P$ $=0.001)$, with a minor effect of abiotic factors $(\mathrm{M}, \rho=0.163, \mathrm{P}=0.001)$. Yet for the specialists, we found strong and significant correlations with the three sets of explanatory variables. The biotic factors $(\mathrm{M}, \rho=0.356, P=0.001)$ were again the stronger drivers of dissimilarities distributions, even after controlling for the effect of geographic distance and abiotic factors (PM, $\rho=0.324, P=0.001$; PM, $\rho=0.318, P=0.001$; respectively). Strong and significant correlations were also observed with abiotic $(\mathrm{M}, \rho=0.325, P=$ $0.001)$, even controlling for geographic distance and biotic factors (PM, $\rho=0.315, P=$ 0.001 ; PM, $\rho=0.281, P=0.001$; respectively), and to a lesser extent to geographic distance $(\mathrm{M}, \rho=0.243, P=0.001)$, even controlling for abiotic and biotic factors (PM, $\rho$ $=0.229, P=0.001 ; \mathrm{PM}, \rho=0.188, P=0.001 ;$ respectively). Evaluating the mesoregional scale, we observed strong and significant correlations only with biotic factors, for both overall bacterial communities $(\mathrm{M}, \rho=0.231, P=0.001)$, generalists $(\mathrm{M}, \rho=0.206, P=$ $0.001)$, and for specialists $(\mathrm{M}, \rho=0.242, P=0.001)$, with lower influence of controlling geographic and abiotic controlling effects.

Later, we forward-selected the factors within the sets of significant parameters that could be driving bacterial, generalists, and specialists diversity distributions across spatial scales, through Partial Mantel tests (Table 3). At overall scale, after controlling all 
658

659

660

661

662

663

664

665

666

667

668

669

670

671

672

673

674

675

676

677

678

679

680

681

682

the possible individual factors with their respective matrices (e.g. $\mathrm{pH}$ controlling for abiotic), the number of nodes was the most important factor for overall bacterial communities (PM, $\rho=0.116, P=0.002)$, whereas no strong factor was found for generalists. Yet for specialists, the number of nodes (PM, $\rho=0.205, P=0.001$ ), and the number of negative edges (PM, $\rho=0.139, P=0.001)$, and to a lesser extent spatial distance (PM, $\rho=0.080, P=0.001)$, were the main factors. When depicting the variability across spatial scales, we noticed different patterns within and over the mesoregional threshold. At the local scale, spatial distance (PM, $\rho=0.241, P=0.001)$, elevation (PM, $\rho=0.227, P=0.001)$, and biopores $(\mathrm{PM}, \rho=0.140, P=0.001)$ were the main drivers of overall bacterial communities. The number of strong and significant correlations was greater for specialists (11 factors) than for generalists (6 factors). Specialists were mainly correlated with spatial distance (PM, $\rho=0.201, P=0.001)$, elevation (PM, $\rho=0.155, P$ $=0.001)$, season $(\mathrm{PM}, \rho=0.133, P=0.001)$, number of nodes $(\mathrm{PM}, \rho=0.127, P=0.001)$, soil type $(\mathrm{PM}, \rho=0.108, P=0.001)$, and average weighted degree $(\mathrm{PM}, \rho=0.106, P=$ 0.001). In comparison, generalists were most correlated with elevation (PM, $\rho=0.228, P$ $=0.001)$, spatial distance $(\mathrm{PM}, \rho=0.216, P=0.001)$, and biopores $(\mathrm{PM}, \rho=0.154, P=$ $0.001)$. At the regional scale, land use (PM, $\rho=0.166, P=0.001)$, the number of negative edges (PM, $\rho=0.121, P=0.001)$, and the number of nodes $(\mathrm{PM}, \rho=0.139, P=0.001)$ were the main factors correlated with bacterial communities. Land use (PM, $\rho=0.131, P$ $=0.001)$ and negative edges $(\mathrm{PM}, \rho=0.122, P=0.001)$ were also the major factors for generalists. Yet for specialists the main constraining factors were number of nodes (PM, $\rho=0.240, P=0.001)$ and negative edges $(\mathrm{PM}, \rho=0.240, P=0.001)$, and to a lesser extent land use (PM, $\rho=0.096, P=0.001)$.

\section{Discussion}


683 The Brazilian Atlantic Forest is recognized as one of the 36 most important hotspots of 684 biodiversity around the globe (Jantz et al. 2015; Weinzettel et al. 2018; de Lima et al. 685 2020), harboring about 1/3 of Brazilian biodiversity and high levels of endemism of both plants and animals (Myers et al. 2000; Ribeiro et al. 2009). As a result, there is an urgent

687 call for the conservation of this threatened and neglected biome. This study has been conceived to advance our understanding of the possible shifts in soil microbial assembly patterns after long-term forest-to-agriculture conversion. Moreover, we have linked the biogeographical patterns of soil microbial communities to the consequences for ecological processes, niche occupancy, and ecosystem services, due to the deforestation of Brazilian tropical and subtropical forests (Mendes et al. 2014, 2015b; Goss-Souza et al. 2019, 2020), focusing on the Subtropical Atlantic Forest (Goss-Souza et al. 2017; Ceola et al. 2021).

\section{Drivers of bacterial assembly patterns and processes across spatial scales}

Linking microbial diversity patterns to the ecological processes governing assembly has been often implemented for local (Ferrenberg et al. 2013; Dini-Andreote et al. 2014; Jia et al. 2018; Tripathi et al. 2018) or regional and continental scales communities (Stegen et al. 2013; Ma et al. 2016, 2017; Luo et al. 2019), often not taking into account the pure geographic effect of spatial distance (i.e. distance-decays) between microbial communities. Moreover, just a few studies have quantified the coupled effects of spatial distance, abiotic and biotic factors on microbial diversity distribution, and ecological processes (Martiny et al. 2011; Gao et al. 2019; Zhao et al. 2019; Ceola et al. 2021). To our knowledge, this is the first study underlying those patterns and processes for bacterial communities across spatial scales, in Brazilian subtropical soils. 

along with land uses, and geographic distance between microbial communities, leading to microbial diversity loss due to forest-to-agriculture conversion. Although we did not find differences in alpha diversity and richness (Supplementary Fig. S3), both long-term forest to no-till and forest to pasture conversions led to changes in bacterial beta-diversity distances (Fig. 1) and consequent loss in pairwise beta diversities (Fig. 2), which is indicative of biotic homogenization (Rodrigues et al. 2013; Maaß et al. 2014; Rocha et al. 2021). These results corroborate our previous study, in which we evaluated, through metagenomics, the patterns of microbial alpha and beta diversities in two out of six counties evaluated here (Goss-Souza et al. 2017). Other authors also have found the same soil microbial patterns for both subtropical (Ceola et al. 2021) and tropical soils (Rodrigues et al. 2013; Mendes et al. 2015b). When comparing seasons for the same land use, we found a loss in pairwise beta diversities from winter to summer in no-till and pasture, the same as found in our previous metagenomics study (Goss-Souza et al. 2017). Moreover, our microbial co-occurrence networks have raised the hypothesis that land-use change has not only altered microbial composition and diversity but has also increased the complexity of the biotic interactions among taxa (Fig. 3; Table 1), just as found in other studies (Mendes et al. 2014; Goss-Souza et al. 2017; Felipe-Lucia et al. 2020). Together, our results emphasize that the long-term forest to agriculture conversion led to a loss in microbial diversity, just as observed in previous studies in tropical (Rodrigues et al. 2013; Mendes et al. 2014, 2015b; Goss-Souza et al. 2019, 2020) and subtropical agroecosystems (Goss-Souza et al. 2017; Ceola et al. 2021).

We also found a significant scale-dependence of DDR for overall bacterial at the local scale $(<97 \mathrm{~km})$ and disappeared at the regional scale, suggesting that, 
732

733

734

735

736

737

738

739

740

741

742

743

744

745

746

747

748

749

750

751

752

753

754

755

756

according to Baas Becking proposal, bacterial communities are widespread across the regional limit, and filtered by environmental factors at local scales (De Wit and Bouvier 2006). Most microbial studies have highlighted the importance of land-use change and soil physical and chemical characteristics (e.g., pH, soil fertility) as the main drivers of local diversity patterns (Brookes et al. 2010; Rodrigues et al. 2013; Lauber et al. 2013; Mueller et al. 2014). Although we observed a loss in bacterial diversity due to land-use change, markedly in summer (Fig. 2) and a scale dependence for all land uses and seasons (Supplementary Fig. S4), mantel tests revealed that land use was only significant at the regional scale (Table 3), as a secondary effect, explaining $16.6 \%$ of the variability. The main drivers at this spatial scale were the biotic factors, as represented the number of nodes $(12.1 \%)$ and negative edges (15.7\%), within other weaker but significant biotic factors, corroborating (Gao et al. 2019). At the local scale, we also found a loss of beta diversities after forest conversion for both no-till and pasture and local scales (Fig. 7a). DDRs were significant for overall bacterial communities across land uses. However, as observed for overall bacterial communities, land use was not a significant factor modulating local microbial diversity, which goes against other findings for local bacterial communities (van der Gast et al. 2011; Hazard et al. 2013; Karimi et al. 2020; Mirza et al. 2020) with season presenting a secondary influence (Table 3). The main drivers of local bacterial communities were spatial distance and elevation. When evaluating the geographical distribution of arbuscular mycorrhizal fungal communities in a broad gradient of land-use intensification and spatial distance, (Ceola et al. 2021) have found significant distance-decays for all land uses, but not directly correlated with the land-use change itself, as the main drivers of decays were soil type, total organic carbon, and clay contents, both considered as evolutionary historical contingencies (Fukami and Nakajima 2011), not related to the contemporary human intervention, as represented by land-use 
757

758

759

760

761

762

763

764

765

766

767

768

769

770

771

772

773

774

775

776

777

778

779

780

781

change and management intensification. Although we cannot deny that this correlation seems to occur widely, we argue that the arbitrary assignment of soil samples to a determined land use could lead to confounding results. While considering land use as a factor, not a treatment (as we did here), we can observe how this single factor behaves when confronted with other measured or calculated environment characteristics that result from forest to agroecosystem conversion. In this sense, Partial Mantel and Multiple Regression of Matrices (MRM) analyses seem to be powerful tools, as they eliminate the possible collinear effect of a single variable when controlling for the original dataset matrix (Lichstein 2007). Thus, we argue that land uses would not be arbitrarily set as treatments, as soil habitats have multiple facets, due to their geographic location, management intensity, soil type and origin, climate conditions, among others (Fierer and Jackson 2006; Delgado-Baquerizo et al. 2018). Together, those soil ecosystem characteristics culminate with different historical (Fukami and Nakajima 2011) and contemporary contingencies (Durrer et al. 2017; Wang et al. 2017; Karimi et al. 2020), leading to different microbial diversity outcomes (Ceola et al. 2021).

In our study, somehow surprisingly, the main filtering factor of bacterial diversities at the overall scale was the number of nodes (biotic factor), explaining $11.6 \%$ of the total variation in beta diversities, as revealed by microbial networks and Mantel tests (Table 1; Fig. 3; Table 3). The main local filters were spatial distance and elevation, which together explained $46.8 \%$ of the total variation, the same as found in previous biogeographic studies (Fierer and Jackson 2006; Pellissier et al. 2014; Wang et al. 2017; Farrer et al. 2019), with a secondary effect of the season (Goss-Souza et al. 2017; Ma et al. 2017), biopores, an abiotic soil physical factor. The average weighted degree was the major biotic filter of bacterial communities at the local scale $(11.9 \%)$, corroborating the findings of a biogeographic study of bacterial communities in paddy soils at a continental 
scale (Gao et al. 2019). The authors also found coupled effect of geographic distance, abiotic and biotic factors, as observed in our study. Those observations are in contrast with several studies that have attributed this local filtering predominantly to habitat characteristics that lead to environmental abiotic selection (Julia et al. 2014; Mendes et al. 2015a; Durrer et al. 2017).

Another possible explanation for the significant DDRs is dispersal limitation, as observed by the low immigration rates we have calculated in our study, particularly for forest and no-till microbial communities (Fig. 6b). These findings are following what we have observed in a metagenomic study where we compared the same land uses in two out of the six counties of the present study (Goss-Souza et al. 2017). Some shreds of evidence against the Baas Becking hypothesis come from studies showing that dispersal of microbes is limited, meaning that "everything is not everywhere", at least at a contemporary pace (Nemergut et al. 2013). By comparing the DDRs of bacterial communities with the patterns found for Eukaryotes, including Fungi (Zhao et al. 2019; Ceola et al. 2021), the decays tend to be lower for Bacteria, but they are often significant, meaning that the higher the distance between pairs of microbial communities, the more contrasting they are (Horner-Devine et al. 2004; Martiny et al. 2006, 2011; Gao et al. 2019). All those results together led us to partially reject our first hypothesis, since the land-use change, despite being significant, was not found as a ruling driver of microbial assembly patterns.

Our second hypothesis stated that (ii) the balance between neutral and niche-based assembly models would differ along land uses, and spatial scales. Our theoretical rank association models based on AIC (Fig. 6a) showed that forest and no-till soil samples fitted most a niche-based model (Lognormal), regarding deterministic assembly processes while pasture soil samples fitted most a neutral-based model (ZSM), related to stochastic 
assembly processes. Moreover, we observed that the balance between stochastic and deterministic assembly varied from winter to summer season, partially confirming our second hypothesis. Once more, our T-RFLP data corroborated our previous metagenomics data (Goss-Souza et al. 2017), suggesting that forest and no-till microbial communities have a niche-based assembly, related to deterministic processes, suggesting that they are more likely to be governed by environmental filtering through the ecological selection process (Stegen et al. 2013; Dini-Andreote et al. 2015). Conversely, pasture communities have a predominantly neutral assembly, regarding stochastic processes modulating microbial assembly patterns, indicating a pivotal role of dispersal ecological process (Albright et al. 2019; Li et al. 2020). We also found a positive correlation between dispersal rates and microbial communities fitting neutral assembly, with pasture samples presenting both higher values of dispersal rates and more samples fitting to stochastic ZSM rank abundance model (Fig. 6b). Together, these results confirm previous theoretical and experimental models suggesting that dispersal has an important role in structuring microbial communities assembly (Hubbell 2005; Martiny et al. 2011; Ferrenberg et al. 2013; Nemergut et al. 2013; Goss-Souza et al. 2020).

Therefore, we depicted the balance between neutral- and niche-based assembly models, according to spatial distance, through Z-scores. At the local scale, we found that forest microbial communities presented, on average, a neutral-based model, related to stochastic processes, but with a large interplay between neutral and niche-based assembly, mainly in the winter season (as represented by the high standard deviation; boxplot, Fig. 7c). No-till microbial communities fitted above the neutral threshold of deviation from null expectation $(+2)$, which indicated that communities were more segregated than expected by chance, regarding deterministic variable selection (DiniAndreote et al. 2015; Gao et al. 2019; Xue et al. 2021). Yet for pasture, most communities 
832 fitted within the neutral-based assembly, regarding stochastic processes, the same as

833 found in our previous metagenomics study (Goss-Souza et al. 2017). At the regional scale

834 (Fig. 7d), forest microbial communities followed a niche-based model, related to 835 deterministic variable selection, differently from what we have found at overall and local 836 scales, but corroborating (Goss-Souza et al. 2017). No-till communities fitted above the 837 null expectation, regarding variable selection, the same as found at the local scale. 838 Meanwhile, pasture communities fitted within the neutral-based assembly, regarding 839 stochastic processes, the same as found for overall and local scales. Ecologically, the 840 assembly of microbial communities is dependent on the trade-offs between local and 841 regional microbial communities, which is dependent on the microbial survival at the local 842 species pool and the colonization potential of microbial species in the regional pool 843 (Pärtel et al. 2017; Bittleston et al. 2020). While distance-decays and dispersal acted on the composition of microbial communities, variable selection and drift altered the relative abundances. Our findings have demonstrated an interplay among stochastic and deterministic processes modulating assembly, at temporal and spatial scales, the same as

847 found for other soil and synthetic microbial communities (Ferrenberg et al. 2013; Nemergut et al. 2013; Stegen et al. 2013; Dini-Andreote et al. 2015; Evans et al. 2017; Goss-Souza et al. 2017, 2020; König et al. 2019).

850

\section{Biogeographic patterns and assembly processes differ between generalists and} specialists

853 Ecologists have long-established the conceptual basis of niche occupancy and habitat specialization for several species of plants and animals (Reznick et al. 2002; Bohn et al. 2014). Several authors have raised the idea of examining microbial life-history strategies to comprehend the patterns and processes that modulate species distribution and trophic 
857 relationships in soils (van der Heyde et al. 2017; Powell and Rillig 2018). Here, we 858 separated species as generalists and specialists, based on the frequency of occurrence and 859 habitat specialization of each OTU into our 324 samples representing bacterial 860 communities. Our third hypothesis affirmed that (iii) the processes governing microbial 861 assembly would vary between habitat generalists and specialists. Our results have shown 862 that forest microbial communities presented the highest proportion of specialists but the lowest values of betweenness centrality, while pasture has presented an opposite pattern.

864 The betweenness centrality is defined as the number of times a node (i.e. taxa) acts as a bridge along the shortest path between two other nodes, which indicates the most important nodes that are interpreted as key taxa with a central role in the community (Poudel et al. 2016; Mendes et al. 2018; Shi et al. 2020). This result indicates that forest communities have presented a higher number of keystones species that are responsible for regulating the structure and dynamics of the community network. On the other hand, pasturelands have presented few keystone taxa but with a higher betweenness centrality. Key taxa are associated with many others, and the removal of these nodes may have a

872 large impact on the community structure (Steele et al. 2011). Thus, the lower number of specialists and keystone species in pasture suggest a less resilient and stress-tolerant community.

As land use did not play a pivotal role in separating bacterial species diversity and distributions, we depicted the overall bacterial OTU patterns and the spatial scale effect, 877 according to microbial life strategies (Barberán et al. 2012; Leff et al. 2015; Gao et al. 2019; Luo et al. 2019). The most prevalent OTUs in our study were found as habitat specialists. Our CLAM tests (Fig. 4) coupled with DDRs (Fig. 5) strongly support a perspective of microbial distribution in which communities are dominated by endemic species and share very few common OTUs between sites and along geographical 
882

883

884

885

886

887

888

889

890

891

892

893

894

895

896

897

898

899

900

901

902

903

904

905

906

gradients (Robeson et al. 2011). This local endemism thesis is here supported by the great influence of dispersal limitation in overall assembly patterns (Figs. 5, 6, and 7). Moreover, the endemic distribution is emphasized by the high significance of geographical distance at the local scale for overall communities (Tables 2 and 3), coupled with the interaction with biotic factors at the local scale for endemic OTUs, just as found in another biogeographic study (Gao et al. 2019). Our DDRs for endemic taxa have shown that decays culminated with high pairwise diversities at larger distances (Luo et al. 2019), directly contradicting the idea of "everything is everywhere". It suggests that the diversity of soil microbial communities, such as the ones found in the Atlantic Forest biome in our study, might be "beyond the borders" of our previous speculations, especially given the prevalence of endemic microbial species. Linking these endemic patterns found for microbial communities in our study with the already existent knowledge about high levels of endemism of animals and, especially plants in the Atlantic forest biome and other global hotspots of biodiversity (Myers et al. 2000; Jantz et al. 2015) is paramount. It also raises the hypothesis that, land use, as a contemporary paced human intervention, it is not a pivotal shaper of microbial niche occupancy and habitat specialization. As we have found in a previous study of AM fungal biogeography in this same biome (Ceola et al. 2021), land use was only significant for overall bacterial communities and generalists and at a regional scale. Our results have shown that other historical contingencies (Fukami and Nakajima 2011; Ceola et al. 2021), as represented by soil type, and seasonal effect, intimately linked to soil formation (Tables 2 and 3), and evolutionary contingencies (Hanson et al. 2012; Wang et al. 2013), linked to dispersal limitation (Figs. 6 and 7) and taxa evolution, may be driving microbial niche breadth (Luo et al. 2019) and habitat specialization (Székely and Langenheder 2014), markedly at local scales. Also, those historical and evolutionary contingencies could be shaping microbial co-occurrence 
patterns and interacting with biotic deterministic selection (i.e. variable selection) (Barberán et al. 2012; Dini-Andreote et al. 2015; Gao et al. 2019).

Soil type is defined by geological and climatic historical contingencies, which together with the activity of microorganisms, water and time regulate rock intemperism and soil formation (Huggett 1998; Egli et al. 2018). According to the World Reference Base for Soil Resources (Anjos et al. 2015), the soils from all sampling sites in the western mesoregion are classified as Red Ferralsols, which are evolved soils with the dominance of kaolinite and Fe oxides. Otherwise, soils from plateau mesoregion are more diverse. Soils from the counties of Lages and Campo Belo do Sul, were classified as Humic Yellow Nitisols, which are strongly structured soils, characterized by low-activity clay, P fixation, the prevalence of Fe oxides, and accumulation of organic matter in the surface while soils from Otacílio Costa County were found to be Humic Cambisols, which are soils with little or no profile differentiation, moderately developed, with the accumulation of organic matter in the surface. We argue that soil type, a historical contingency (together with dispersal, an evolutionary contingency), could be locally filtering taxa distributions more strongly than the influence of land-use change, which is historically recent, as all the sites were converted from the forest into agroecosystems in the last decades (Bartz et al. 2014; Goss-Souza et al. 2017; Ceola et al. 2021).

We can reach a more comprehensive view of biodiversity, by integrating belowground microbial diversity and aboveground plant diversity, when studying microbial communities in terms of shifts in relative abundances using weighted resemblances (e.g. Bray-Curtis), as we performed here. Some theoretical reviews and experimental studies have shown that applying those simpler rules and resolutions would allow ecologists to integrate microbial and macrobial patterns of diversity (Soininen et al. 2007; Astorga et al. 2012; Shade et al. 2018). In our case, these implementations will 
932 allow, in the next step, comparisons between belowground microbial diversity and 933 aboveground plant diversity patterns, to advance our understanding of how the historical 934 contingencies could be driving not only macrobial endemism (Myers et al. 2000; Vale et 935 al. 2018) in the Atlantic Forest biome but also the microbial endemism, as observed in 936 the present and previous studies from our group (Goss-Souza et al. 2017; Ceola et al. 937 2021). As an outcome, those linked results will enable ecologists to gather important 938 datasets for land occupation, use, and management modeling. Meanwhile, policymakers 939 may use this integrative information for establishing environmental monitoring and conservation strategies, to safeguard supporting ecosystem services, dependent on microbial activity (e.g. carbon and nutrient cycling), which are linked to provisioning and

942 regulating services, such as food production, carbon storage, and GHG emissions/mitigation at the Atlantic Forest and other subtropical and tropical hotspots of biodiversity.

\section{Conclusions}

947 This study represented a step forward to depict the biogeographic patterns of bacterial communities due to land-use change in a broader geographic scale, in the subtropical Atlantic Forest biome. We have shown that soil bacterial diversity and niche occupancy are shaped by geographic spatial distance and long-term historical contingencies related to the soil origin (e.g. soil type and climate), that culminate with important coupled 952 patterns of dispersal limitation and significant distance-decays of beta diversities. We also demonstrated that — differently from the "everything is everywhere" niche postulationstochastic processes, represented by the dispersal limitation act to outweigh the effect of the deterministic selection process caused by soil historical contingencies and the

956 formation of small geographic islands, shaped by soil type and climate. Those patterns 
957

958

959

960

961

962

963

964

965

966

967

968

969

970

971

972

973

974

975

976

977

978

979

980

981

982

983

984

985

986

987

988

are inflated when evaluation microbial niche specialists, markedly at a local scale, with consequences for biotic interactions among members from local microbial communities.

Differently from several other microbiological local and biogeographical studies, landuse change was not found a major driver of microbial patterns and processes.

\section{References}

Albright MBN, Chase AB, Martiny JBH (2019) Experimental Evidence that Stochasticity Contributes to Bacterial Composition and Functioning in a Decomposer Community. MBio 10:1-13. https://doi.org/10.1128/mbio.00568-19

Alef K, Nannipieri P (1995) Methods in Applied Soil Microbiology and Biochemistry, 1 st edn. Elsevier, London

Anderson MJ (2001) A new method for non-parametric multivariate analysis of variance. Austral Ecol 26:32-46. https://doi.org/10.1046/j.14429993.2001.01070.x

Anderson TH, Domsch KH (1993) The metabolic quotient for CO2 (qCO2) as a specific activity parameter to assess the effects of environmental conditions, such as $\mathrm{pH}$, on the microbial biomass of forest soils. Soil Biol Biochem 25:393-395. https://doi.org/10.1016/0038-0717(93)90140-7

Anjos L, Gaistardo, Carlos Cruz; Deckers J, Dondeyne, Stefaan; Eberhardt, Einar; Gerasimova M, et al (2015) World reference base for soil resources 2014 International soil classification system for naming soils and creating legends for soil maps. FAO, Rome

Astorga A, Oksanen J, Luoto M, et al (2012) Distance decay of similarity in freshwater communities: Do macro- and microorganisms follow the same rules? Glob Ecol Biogeogr 21:365-375. https://doi.org/10.1111/j.1466-8238.2011.00681.x

Barberán A, Bates ST, Casamayor EO, Fierer N (2012) Using network analysis to explore co-occurrence patterns in soil microbial communities. ISME J 6:343-351. https://doi.org/10.1038/ismej.2011.119

Bartz MLC, Brown GG, da Rosa MG, et al (2014) Earthworm richness in land-use systems in Santa Catarina, Brazil. Appl Soil Ecol 83:59-70. https://doi.org/10.1016/j.apsoil.2014.03.003

Baselga A (2017) Partitioning abundance-based multiple-site dissimilarity into 
components: balanced variation in abundance and abundance gradients. Methods Ecol Evol 8:799-808. https://doi.org/10.1111/2041-210X.12693

Baselga A, Orme D, Villeger S, et al (2018) betapart: Partitioning Beta Diversity into Turnover and Nestedness Components.

Bastian M, Heymann S, Jacomy M (2009) Gephi: an open source software for exploring and manipulating networks. In: International AAAI Conference on Weblogs and Social Media. San Jose

Bittleston LS, Gralka M, Leventhal GE, et al (2020) Context-dependent dynamics lead to the assembly of functionally distinct microbial communities. Nat Commun 11:1-10. https://doi.org/10.1038/s41467-020-15169-0

Blanchet FG, Cazelles K, Gravel D (2020) Co-occurrence is not evidence of ecological interactions. Ecol Lett 23:1050-1063

Bohn K, Pavlick R, Reu B, Kleidon A (2014) The strengths of r- And K-selection shape diversity-disturbance relationships. PLoS One 9:e95659. https://doi.org/10.1371/journal.pone.0095659

Bozdogan H (1987) Model selection and Akaike's Information Criterion (AIC): The general theory and its analytical extensions. Psychometrika 52:345-370. https://doi.org/10.1007/BF02294361

Brinkmann N, Schneider D, Sahner J, et al (2019) Intensive tropical land use massively shifts soil fungal communities. Sci Rep 9:1-11. https://doi.org/10.1038/s41598019-39829-4

Brody JR, Kern SE (2004) Sodium boric acid: a Tris-free, cooler conductive medium for DNA electrophoresis. Biotechniques 36:214-216

Brookes PC, Lauber CL, Rousk J, et al (2010) Soil bacterial and fungal communities across a pH gradient in an arable soil. 1340-1351. https://doi.org/10.1038/ismej.2010.58

Cambardella CA, Elliott ET (1992) Particulate Soil Organic-Matter Changes across a Grassland Cultivation Sequence. Soil Sci Soc Am J 56:777-783. https://doi.org/10.2136/sssaj 1992.03615995005600030017x

Ceola G, Goss-Souza D, Alves J, et al (2021) Biogeographic Patterns of Arbuscular Mycorrhizal Fungal Communities Along a Land-Use Intensification Gradient in the Subtropical Atlantic Forest Biome. Microb Ecol. https://doi.org/10.1007/s00248-021-01721-y

Chazdon RL, Chao A, Colwell RK, et al (2011) A novel statistical method for 
classifying habitat generalists and specialists. Ecology 92:1332-1343. https://doi.org/10.1890/10-1345.1

Claessen MEC, Barreto WO, Paula JL, Duarte MN (1997) Manual of soil analysis methods, 2nd edn. Embrapa, Rio de Janeiro

Cordovez V, Dini-Andreote F, Carrión VJ, Raaijmakers JM (2019) Ecology and Evolution of Plant Microbiomes. Annu Rev Microbiol 73:annurev-micro-090817062524. https://doi.org/10.1146/annurev-micro-090817-062524

Cottenie K (2005) Integrating environmental and spatial processes in ecological community dynamics. Ecol Lett 8:1175-1182. https://doi.org/10.1111/j.14610248.2005.00820.x

Creamer RE, Hannula SE, Leeuwen JPV, et al (2016) Ecological network analysis reveals the inter-connection between soil biodiversity and ecosystem function as affected by land use across Europe. Appl Soil Ecol 97:112-124. https://doi.org/10.1016/j.apsoil.2015.08.006

de Lima RAF, Oliveira AA, Pitta GR, et al (2020) The erosion of biodiversity and biomass in the Atlantic Forest biodiversity hotspot. Nat Commun 11:1-16. https://doi.org/10.1038/s41467-020-20217-w

De Vrieze J, Ijaz UZ, Saunders AM, Theuerl S (2018) Terminal restriction fragment length polymorphism is an "old school" reliable technique for swift microbial community screening in anaerobic digestion. Sci Rep 8:20-22. https://doi.org/10.1038/s41598-018-34921-7

De Wit R, Bouvier T (2006) "Everything is everywhere, but, the environment selects"; what did Baas Becking and Beijerinck really say? Environ Microbiol 8:755-758. https://doi.org/10.1111/j.1462-2920.2006.01017.x

Delgado-Baquerizo M, Oliverio AM, Brewer TE, et al (2018) A global atlas of the dominant bacteria found in soil. Science (80- ) 359:320-325. https://doi.org/10.1126/science.aap9516

Dexter AR (1988) Advances in characterization of soil structure. Soil Tillage Res $11: 199-238$

Dexter AR, Czyz EA, Gaţe OP (2007) A method for prediction of soil penetration resistance. Soil Tillage Res 93:412-419. https://doi.org/10.1016/j.still.2006.05.011

Dhaliwal GS, Gupta N, Kukal SS, Kaur M (2011) Standardization of automated Vario EL III CHNS analyzer for total carbon and nitrogen determination in soils. Commun Soil Sci Plant Anal 42:971-979. 
https://doi.org/10.1080/00103624.2011.558965

Dini-Andreote F, de Cássia Pereira e Silva M, Triadó-Margarit X, et al (2014)

Dynamics of bacterial community succession in a salt marsh chronosequence: evidences for temporal niche partitioning. ISME J 8:1989-2001. https://doi.org/10.1038/ismej.2014.54

Dini-Andreote F, Stegen JC, van Elsas JD, Salles JF (2015) Disentangling mechanisms that mediate the balance between stochastic and deterministic processes in microbial succession. Proc Natl Acad Sci 201414261. https://doi.org/10.1073/pnas.1414261112

Dumbrell AJ, Nelson M, Helgason T, et al (2010) Relative roles of niche and neutral processes in structuring a soil microbial community. ISME J 4:337-345. https://doi.org/10.1038/ismej.2009.122

Durrer A, Gumiere T, Taketani RG, et al (2017) The drivers underlying biogeographical patterns of bacterial communities in soils under sugarcane cultivation. Appl Soil Ecol 110:12-20. https://doi.org/10.1016/j.apsoil.2016.11.005

Edwards U, Rogall T, Blöcker H, et al (1989) Isolation and direct complete nucleotide determination of entire genes. Characterization of a gene coding for $16 \mathrm{~S}$ ribosomal RNA. Nucleic Acids Res 17:7843-7853. https://doi.org/10.1093/nar/17.19.7843

Egli M, Hunt AG, Dahms D, et al (2018) Prediction of soil formation as a function of age using the percolation theory approach. Front Environ Sci 6:1-21. https://doi.org/10.3389/fenvs.2018.00108

Etienne RS, Alonso D (2005) A dispersal-limited sampling theory for species and alleles. Ecol Lett 8:1147-1156. https://doi.org/10.1111/j.1461-0248.2005.00817.x

Evans S, Martiny JBH, Allison SD (2017) Effects of dispersal and selection on stochastic assembly in microbial communities. ISME J 11:176-185. https://doi.org/10.1038/ismej.2016.96

Fan K, Cardona C, Li Y, et al (2017) Rhizosphere-associated bacterial network structure and spatial distribution differ significantly from bulk soil in wheat crop fields. Soil Biol Biochem 113:275-284. https://doi.org/10.1016/j.soilbio.2017.06.020

Faoro H, Alves AC, Souza EM, et al (2010) Influence of soil characteristics on the diversity of bacteria in the southern brazilian atlantic forest. Appl Environ Microbiol 76:4744-4749. https://doi.org/10.1128/AEM.03025-09

Farrer EC, Porazinska DL, Spasojevic MJ, et al (2019) Soil Microbial Networks Shift Across a High-Elevation Successional Gradient. Front Microbiol 10:1-13. 
1091

1092

1093

1094

1095

1096

1097

1098

1099

1100

1101

1102

1103

1104

1105

1106

1107

1108

1109

1110

1111

1112

1113

1114

1115

1116

1117

1118

1119

1120

1121

1122

1123

1124

https://doi.org/10.3389/fmicb.2019.02887

Felipe-Lucia MR, Soliveres S, Penone C, et al (2020) Land-use intensity alters networks between biodiversity, ecosystem functions, and services. Proc Natl Acad Sci 117:28140-28149. https://doi.org/10.1073/pnas.2016210117

Feng M, Tripathi BM, Shi Y, et al (2019) Interpreting distance- decay pattern of soil bacteria via quantifying the assembly processes at multiple spatial scales. Microbiologyopen e851. https://doi.org/10.1002/mbo3.851

Ferrenberg S, O’Neill SP, Knelman JE, et al (2013) Changes in assembly processes in soil bacterial communities following a wildfire disturbance. ISME J 7:1102-1111. https://doi.org/10.1038/ismej.2013.11

Fierer N, Jackson RB (2006) The diversity and biogeography of soil bacterial communities. Proc Natl Acad Sci U S A 103:626-631. https://doi.org/10.1073/pnas.0507535103

Friedman J, Alm EJ (2012) Inferring Correlation Networks from Genomic Survey Data. PLoS Comput Biol 8:1-11. https://doi.org/10.1371/journal.pcbi.1002687

Fukami T, Nakajima M (2011) Community assembly: Alternative stable states or alternative transient states? Ecol Lett 14:973-984. https://doi.org/10.1111/j.14610248.2011.01663.x

Gao Q, Yang Y, Feng J, et al (2019) The spatial scale dependence of diazotrophic and bacterial community assembly in paddy soil. Glob Ecol Biogeogr 28:1093-1105. https://doi.org/10.1111/geb.12917

Gee GW, Bauder JW (1986) Particle-size analysis. In: Klute A (ed) Methods of soil analysis. ASA, Madison, pp 383-411

Gómez-Rodríguez C, Baselga A (2018) Variation among European beetle taxa in patterns of distance decay of similarity suggests a major role of dispersal processes. Ecography (Cop) 41:1825-1834. https://doi.org/10.1111/ecog.03693

Goss-Souza D, Mendes LW, Borges CD, et al (2017) Soil microbial community dynamics and assembly under long-term land use change. FEMS Microbiol Ecol 93:fix109. https://doi.org/10.1093/femsec/fix109

Goss-Souza D, Mendes LW, Rodrigues JLM, Tsai SM (2019) Amazon forest-toagriculture conversion alters rhizosphere microbiome composition while functions are kept. FEMS Microbiol Ecol 95:fiz009. https://doi.org/10.1093/femsec/fiz009

Goss-Souza D, Mendes LW, Rodrigues JLM, Tsai SM (2020) Ecological Processes Shaping Bulk Soil and Rhizosphere Microbiome Assembly in a Long-Term 
Amazon Forest-to-Agriculture Conversion. Microb Ecol 79:110-122. https://doi.org/10.1007/s00248-019-01401-y

Hanson CA, Fuhrman JA, Horner-Devine MC, Martiny JBH (2012) Beyond biogeographic patterns: Processes shaping the microbial landscape. Nat Rev Microbiol 10:497-506. https://doi.org/10.1038/nrmicro2795

Hazard C, Gosling P, Van Der Gast CJ, et al (2013) The role of local environment and geographical distance in determining community composition of arbuscular mycorrhizal fungi at the landscape scale. ISME J 7:498-508. https://doi.org/10.1038/ismej.2012.127

Horner-Devine MC, Lage M, Hughes JB, Bohannan BJM (2004) A taxa-area relationship for bacteria. Nature 432:750-753. https://doi.org/10.1038/nature03073

Hovatter SR, Dejelo C, Case AL, Blackwood CB (2011) Metacommunity organization of soil microorganisms depends on habitat defined by presence of Lobelia siphilitica plants. Ecology 92:57-65

Hubbell SP (2005) Neutral theory in community ecology and the hypothesis of functional equivalence. Funct Ecol 19:166-172. https://doi.org/10.1111/j.02698463.2005.00965.x

Huggett RJ (1998) Soil chronosequences, soil development, and soil evolution: A critical review. Catena 32:155-172. https://doi.org/10.1016/S0341-8162(98)000538

Jabot F, Etienne RS, Chave J (2008) Reconciling neutral community models and environmental filtering: Theory and an empirical test. Oikos. https://doi.org/10.1111/j.0030-1299.2008.16724.x

Jantz SM, Barker B, Brooks TM, et al (2015) Future habitat loss and extinctions driven by land-use change in biodiversity hotspots under four scenarios of climate-change mitigation. Conserv Biol 29:1122-1131. https://doi.org/10.1111/cobi.12549

Jesus EC, Marsh TL, Tiedje JM, Moreira FM (2009) Changes in land use alter the structure of bacterial communities in Western Amazon soils. ISME J 3:1004-1011. https://doi.org/10.1038/ismej.2009.47

Jia X, Dini-Andreote F, Falcão Salles J (2018) Community Assembly Processes of the Microbial Rare Biosphere. Trends Microbiol. https://doi.org/10.1016/j.tim.2018.02.011

Jones CM, Hallin S (2019) Geospatial variation in co-occurrence networks of nitrifying microbial guilds. Mol Ecol 28:293-306. https://doi.org/10.1111/mec.14893 
Julia M, Brossi DL, Mendes LW, et al (2014) Assessment of Bacterial bph Gene in Amazonian Dark Earth and Their Adjacent Soils. 9:. https://doi.org/10.1371/journal.pone.0099597

Kaiser K, Wemheuer B, Korolkow V, et al (2016) Driving forces of soil bacterial community structure, diversity, and function in temperate grasslands and forests. Sci Rep 6:1-12. https://doi.org/10.1038/srep33696

Karczewski K, Riss HW, Meyer EI (2017) Comparison of DNA-fingerprinting (TRFLP) and high-throughput sequencing (HTS) to assess the diversity and composition of microbial communities in groundwater ecosystems. Limnologica 67:45-53. https://doi.org/10.1016/j.limno.2017.10.001

Kari A, Nagymáté Z, Romsics C, et al (2019) Monitoring of soil microbial inoculants and their impact on maize (Zea mays L.) rhizosphere using T-RFLP molecular fingerprint method. Appl Soil Ecol 138:233-244. https://doi.org/10.1016/j.apsoil.2019.03.010

Karimi B, Villerd J, Dequiedt S, et al (2020) Biogeography of soil microbial habitats across France. Glob Ecol Biogeogr 29:1399-1411. https://doi.org/10.1111/geb.13118

Keeney DR, Nelson DW (1982) Nitrogen - inorganic forms. In: Page AL (ed) Methods in Soil Analysis, part 2, 2nd edn. ASA and SSSA, Madison, pp 643-698

Keil P (2019) Z-scores unite pairwise indices of ecological similarity and association for binary data. Ecosphere 10:1-7. https://doi.org/10.1002/ecs2.2933

König S, Köhnke MC, Firle A-L, et al (2019) Disturbance Size Can Be Compensated for by Spatial Fragmentation in Soil Microbial Ecosystems. Front Ecol Evol 7:111. https://doi.org/10.3389/fevo.2019.00290

Lange M, Eisenhauer N, Sierra CA, et al (2015) Plant diversity increases soil microbial activity and soil carbon storage. Nat Commun 6:. https://doi.org/10.1038/ncomms7707

Lauber CL, Ramirez KS, Aanderud Z, et al (2013) Temporal variability in soil microbial communities across land-use types. ISME J 7:1641-1650. https://doi.org/10.1038/ismej.2013.50

Leff JW, Jones SE, Prober SM, et al (2015) Consistent responses of soil microbial communities to elevated nutrient inputs in grasslands across the globe. Proc Natl Acad Sci U S A 112:10967-10972. https://doi.org/10.1073/pnas.1508382112 Legendre P, Fortin M-J (1989) Spatial pattern and ecological analysis. Vegetatio 
80:107-138

Leibold MA, Holyoak M, Mouquet N, et al (2004) The metacommunity concept: a framework for multi-scale community ecology. Ecol Lett 7:601-613. https://doi.org/10.1111/j.1461-0248.2004.00608.x

Lepš J, Šmilauer P (2005) Multivariate Analysis of Ecological Data using CANOCO. Bull Ecol Soc Am 86:6-6. https://doi.org/10.1890/00129623(2005)86[6a:MAOEDU]2.0.CO;2

Li S peng, Wang P, Chen Y, et al (2020) Island biogeography of soil bacteria and fungi: similar patterns, but different mechanisms. ISME J 14:1886-1896. https://doi.org/10.1038/s41396-020-0657-8

Li X, Jousset A, de Boer W, et al (2019) Legacy of land use history determines reprogramming of plant physiology by soil microbiome. ISME J 13:738-751. https://doi.org/10.1038/s41396-018-0300-0

Li Y, Wu X, Chen T, et al (2018) Plant phenotypic traits eventually shape its microbiota: A common garden test. Front Microbiol 9:1-13. https://doi.org/10.3389/fmicb.2018.02479

Lichstein JW (2007) Multiple regression on distance matrices: A multivariate spatial analysis tool. Plant Ecol 188:117-131. https://doi.org/10.1007/s11258-006-9126-3

Luo Z, Liu J, Zhao P, et al (2019) Biogeographic patterns and assembly mechanisms of bacterial communities differ between habitat generalists and specialists across elevational gradients. Front Microbiol 10:1-14. https://doi.org/10.3389/fmicb.2019.00169

Ma B, Dai Z, Wang H, et al (2017) Distinct Biogeographic Patterns for Archaea, Bacteria, and Fungi along the Vegetation Gradient at the Continental Scale in Eastern China. mSystems 2:1-14. https://doi.org/10.1128/msystems.00174-16

Ma B, Wang H, Dsouza M, et al (2016) Geographic patterns of co-occurrence network topological features for soil microbiota at continental scale in eastern China. ISME J 10:1891-1901. https://doi.org/10.1038/ismej.2015.261

Maaß S, Migliorini M, Rillig MC, Caruso T (2014) Disturbance, neutral theory, and patterns of beta diversity in soil communities. Ecol Evol 4:4766-4774. https://doi.org/10.1002/ece3.1313

Martiny JBH, Bohannan BJM, Brown JH, et al (2006) Microbial biogeography: Putting microorganisms on the map. Nat Rev Microbiol 4:102-112. https://doi.org/10.1038/nrmicro1341 
Martiny JBH, Eisen JA, Penn K, et al (2011) Drivers of bacterial $\beta$-diversity depend on spatial scale. Proc Natl Acad Sci U S A 108:7850-7854. https://doi.org/10.1073/pnas.1016308108

Mendes LW, de Lima Brossi MJ, Kuramae EE, Tsai SM (2015a) Land-use system shapes soil bacterial communities in Southeastern Amazon region. Appl Soil Ecol 95:151-160. https://doi.org/10.1016/j.apsoil.2015.06.005

Mendes LW, Kuramae EE, Navarrete AA, et al (2014) Taxonomical and functional microbial community selection in soybean rhizosphere. ISME J 8:1-11. https://doi.org/10.1038/ismej.2014.17

Mendes LW, Raaijmakers JM, De Hollander M, et al (2018) Influence of resistance breeding in common bean on rhizosphere microbiome composition and function. ISME J 12:212-224. https://doi.org/10.1038/ismej.2017.158

Mendes LW, Tsai SM, Navarrete AA, et al (2015b) Soil-Borne Microbiome: Linking Diversity to Function. Microb Ecol 70:255-265. https://doi.org/10.1007/s00248014-0559-2

Meyer KM, Klein AM, Rodrigues JLM, et al (2017) Conversion of Amazon rainforest to agriculture alters community traits of methane-cycling organisms. Mol Ecol 26:1547-1556. https://doi.org/10.1111/mec.14011

Meyer KM, Memiaghe H, Korte L, et al (2018) Why do microbes exhibit weak biogeographic patterns? ISME J 12:1404-1413. https://doi.org/10.1038/s41396018-0103-3

Mirza BS, McGlinn DJ, Bohannan BJM, et al (2020) Diazotrophs show signs of restoration in Amazon rain forest soils with ecosystem rehabilitation. Appl Environ Microbiol 86:1-10. https://doi.org/10.1128/AEM.00195-20

Mueller RC, Paula FS, Mirza BS, et al (2014) Links between plant and fungal communities across a deforestation chronosequence in the Amazon rainforest. ISME J 8:1548-1550. https://doi.org/10.1038/ismej.2013.253

Myers N, Mittermeier RA, Mittermeier CG, et al (2000) Biodiversity hotspots for conservation priorities. Nature 403:853-558. https://doi.org/10.1038/35002501

Nekola JC, Mcgill BJ (2014) Scale dependency in the functional form of the distance decay relationship. Ecography (Cop) 37:309-320. https://doi.org/10.1111/j.16000587.2013.00407.x

Nemergut DR, Schmidt SK, Fukami T, et al (2013) Patterns and processes of microbial community assembly. Microbiol Mol Biol Rev 77:342-356. 
https://doi.org/10.1128/MMBR.00051-12

Oksanen J, Blanchet FG, Friendly M, et al (2019) vegan: Community Ecology Package. $\mathrm{R}$ package version 2.5-6. 104

Pärtel M, Öpik M, Moora M, et al (2017) Historical biome distribution and recent human disturbance shape the diversity of arbuscular mycorrhizal fungi. New Phytol 227-238. https://doi.org/10.1111/nph.14695

Paula FS, Rodrigues JLM, Zhou J, et al (2014) Land use change alters functional gene diversity, composition and abundance in Amazon forest soil microbial communities. Mol Ecol 23:2988-2999. https://doi.org/10.1111/mec.12786

Pedrinho A, Mendes LW, Merloti LF, et al (2019) Forest-to-pasture conversion and recovery based on assessment of microbial communities in Eastern Amazon rainforest. FEMS Microbiol Ecol 95:1-10. https://doi.org/10.1093/femsec/fiy236

Pellissier L, Niculita-Hirzel H, Dubuis A, et al (2014) Soil fungal communities of grasslands are environmentally structured at a regional scale in the Alps. Mol. Ecol. 23:4274-4290

Poudel R, Jumpponen A, Schlatter DC, et al (2016) Microbiome Networks: A Systems Framework for Identifying Candidate Microbial Assemblages for Disease Management. Phytopathology 106:1083-1096. https://doi.org/10.1094/PHYTO02-16-0058-FI

Powell JR, Karunaratne S, Campbell CD, et al (2015) Deterministic processes vary during community assembly for ecologically dissimilar taxa. Nat Commun 6:1-10. https://doi.org/10.1038/ncomms9444

Powell JR, Rillig MC (2018) Biodiversity of arbuscular mycorrhizal fungi and ecosystem function. New Phytol 220:1059-1075. https://doi.org/10.1111/nph.15119

Ranjard L, Dequiedt S, Chemidlin Prévost-Bouré N, et al (2013) Turnover of soil bacterial diversity driven by wide-scale environmental heterogeneity. Nat Commun 4:1-10. https://doi.org/10.1038/ncomms2431

Reznick D, Bryant MJ, Bashey F (2002) r- and K-selection revisited: The role of population regulation in life-history evolution. Ecology 83:1509-1520. https://doi.org/10.1890/0012-9658(2002)083[1509:raksrt]2.0.co;2

Ribeiro MC, Metzger JP, Martensen AC, et al (2009) The Brazilian Atlantic Forest: How much is left, and how is the remaining forest distributed? Implications for conservation. Biol Conserv 142:1141-1153. 
https://doi.org/10.1016/j.biocon.2009.02.021

Robeson MS, King AJ, Freeman KR, et al (2011) Soil rotifer communities are extremely diverse globally but spatially autocorrelated locally. Proc Natl Acad Sci U S A 108:4406-4410. https://doi.org/10.1073/pnas.1012678108

Rocha FI, Ribeiro TG, Fontes MA, et al (2021) Land-Use System and Forest Floor Explain Prokaryotic Metacommunity Structuring and Spatial Turnover in Amazonian Forest-to-Pasture Conversion Areas. Front Microbiol 12:1-13. https://doi.org/10.3389/fmicb.2021.657508

Rodrigues JLM, Pellizari VH, Mueller R, et al (2013) Conversion of the Amazon rainforest to agriculture results in biotic homogenization of soil bacterial communities. Proc Natl Acad Sci U S A 110:988-993. https://doi.org/10.1073/pnas.1220608110

Rodríguez-Valdecantos G, Manzano M, Sánchez R, et al (2017) Early successional patterns of bacterial communities in soil microcosms reveal changes in bacterial community composition and network architecture, depending on the successional condition. Appl Soil Ecol 120:44-54. https://doi.org/10.1016/j.apsoil.2017.07.015

Schütte UME, Abdo Z, Bent SJ, et al (2008) Advances in the use of terminal restriction fragment length polymorphism (T-RFLP) analysis of 16S rRNA genes to characterize microbial communities. Appl Microbiol Biotechnol 80:365-380. https://doi.org/10.1007/s00253-008-1565-4

Sengupta A, Stegen JC, Neto AAM, Wang Y (2019) Assessing Microbial Community Patterns During Incipient Soil Formation From Basalt. 1-18

Shade A, Dunn RR, Blowes SA, et al (2018) Macroecology to Unite All Life, Large and Small. 1-14

Shi Y, Delgado-Baquerizo M, Li Y, et al (2020) Abundance of kinless hubs within soil microbial networks are associated with high functional potential in agricultural ecosystems. Environ Int 142:105869. https://doi.org/10.1016/j.envint.2020.105869

Soininen J, McDonald R, Hillebrand H (2007) The distance decay of similarity in ecological communities. Ecography (Cop) 30:3-12. https://doi.org/10.1111/j.09067590.2007.04817.x

Sparling G, West A (1988) A direct extraction method to estimate soil microbial C: calibration in situ using microbial respiration and 14C labelled cells. Soil Biol Biochem 20:337-343

Sparling GP (1992) Ratio of microbial biomass carbon to soil organic carbon as a 
sensitive indicator of changes in soil organic matter. Aust J Soil Res 30:195-207. https://doi.org/10.1071/SR9920195

Steele JA, Countway PD, Xia L, et al (2011) Marine bacterial, archaeal and protistan association networks reveal ecological linkages. ISME J 5:1414-1425. https://doi.org/10.1038/ismej.2011.24

Stegen JC, Lin X, Fredrickson JK, et al (2013) Quantifying community assembly processes and identifying features that impose them. ISME J 7:2069-2079. https://doi.org/10.1038/ismej.2013.93

Székely AJ, Langenheder S (2014) The importance of species sorting differs between habitat generalists and specialists in bacterial communities. FEMS Microbiol Ecol 87:102-112. https://doi.org/10.1111/1574-6941.12195

Team RC (2019) R: A language and environment for statistical computing

Tedesco MJ, Gianello C, Bissani CA, et al (1995) Analysis of soil, plants and other materials. Universidade Federal do Rio Grande do Sul, Porto Alegre

Teixeira PC, Donagemma GK, Fontana A, Teixeira WG (2017) Manual de Métodos de Análise de Solo, 3rd edn. EMBRAPA Solos, Brasília

Tripathi BM, Stegen JC, Kim M, et al (2018) Soil pH mediates the balance between stochastic and deterministic assembly of bacteria. ISME J 12:1072-1083. https://doi.org/10.1038/s41396-018-0082-4

Turner S, Pryer KM, Miao VPW, Palmer JD (1999) Investigating deep phylogenetic relationships among cyanobacteria and plastids by small subunit rRNA sequence analysis. J Eukaryot Microbiol 46:327-338

Ulrich W, Gotelli NJ (2010) Null model analysis of species associations using abundance data. Ecology 91:3384-3397. https://doi.org/10.1890/09-2157.1

Vale MM, Tourinho L, Lorini ML, et al (2018) Endemic birds of the Atlantic Forest: traits, conservation status, and patterns of biodiversity. J F Ornithol 89:193-206. https://doi.org/10.1111/jofo.12256

van der Gast CJ, Gosling P, Tiwari B, Bending GD (2011) Spatial scaling of arbuscular mycorrhizal fungal diversity is affected by farming practice. Environ Microbiol 13:241-9. https://doi.org/10.1111/j.1462-2920.2010.02326.x

van der Heyde M, Ohsowski B, Abbott LK, Hart M (2017) Arbuscular mycorrhizal fungus responses to disturbance are context-dependent. Mycorrhiza 27:431-440. https://doi.org/10.1007/s00572-016-0759-3

van Dorst J, Bissett A, Palmer AS, et al (2014) Community fingerprinting in a 
sequencing world. FEMS Microbiol Ecol 89:316-330.

https://doi.org/10.1111/1574-6941.12308

Vega-Avila AD, Gumiere T, Andrade PAMM, et al (2014) Bacterial communities in the rhizosphere of Vitis vinifera L. cultivated under distinct agricultural practices in Argentina. Antonie van Leeuwenhoek, Int J Gen Mol Microbiol. https://doi.org/10.1007/s10482-014-0353-7

Wang J, Shen J, Wu Y, et al (2013) Phylogenetic beta diversity in bacterial assemblages across ecosystems: deterministic versus stochastic processes. ISME J 7:13101321. https://doi.org/10.1038/ismej.2013.30

Wang L, Han M, Li X, et al (2020) Niche and Neutrality Work Differently in Microbial Communities in Fluidic and Non-fluidic Ecosystems. Microb Ecol 79:527-538

Wang XB, Lü XT, Yao J, et al (2017) Habitat-specific patterns and drivers of bacterial $\beta$-diversity in China's drylands. ISME J. https://doi.org/10.1038/ismej.2017.11

Weinzettel J, Vačkáŕ D, Medková H (2018) Human footprint in biodiversity hotspots. Front Ecol Environ 16:447-452. https://doi.org/10.1002/fee.1825

Xue R, Zhao K, Yu X, et al (2021) Deciphering sample size effect on microbial biogeographic patterns and community assembly processes at centimeter scale. Soil Biol Biochem 156:108218. https://doi.org/10.1016/j.soilbio.2021.108218

Zhao J, Gao Q, Zhou J, et al (2019) The scale dependence of fungal community distribution in paddy soil driven by stochastic and deterministic processes. Fungal Ecol 42:100856. https://doi.org/https://doi.org/10.1016/j.funeco.2019.07.010

\section{FIGURE LEGENDS}

Fig. 1 Principal Coordinates Analysis (PCoA) of soil microbial communities across land uses, in the subtropical Atlantic Forest Biome, Southern Brazil. Plots were generated using Bray-Curtis distance matrices with 1000 Monte-Carlo permutations. Samples are colored as follow: forest, green circles; no-till, brown circles; pasture, red circles; Differences in microbial beta diversities clustering among land-uses were evaluated through Adonis-PERMANOVA $\left(\mathrm{n}=324\right.$ samples; 999 permutations; $\left.\mathrm{P}_{\text {ADONIS }}<0.05\right)$.

Fig. 2 Beta diversity distributions between pairs of microbial communities across seasons and land uses, in the Brazilian Atlantic Rainforest Biome, Southern Brazil. (a) Forest winter; (b) Forest summer; (c) No-till winter; (d) No-till summer; (e) Pasture winter, and; (f) Pasture summer. Histograms show the distribution of observed pairwise Bray-Curtis dissimilarities ( $\mathrm{x}$ axis) and the frequency of pairwise beta diversities for each diversity rank bin (y axis). Probability Kernel densities are represented by the blue lines. Pairwise distributions were compared through Kruskal-Wallis (chi-square) non-parametric test with Bonferroni correction. Uppercase letters represent differences between seasons for 
the same land use while lowercase letters represent differences among land uses for the same season $\left(P_{\text {corrected }}<0.05\right)$. The red dashed lines represent the mean beta Bray-Curtis dissimilarity for each set of comparisons $(n=54$ samples; 1341 beta pairwise comparisons). $\beta_{\mathrm{BC}}-$ Beta Bray-Curtis dissimilarity.

Fig. 3 Overall SparCC network plots of co-occurrence and co-exclusion between OTUs, following long-term land use change and seasons. Only OTUs with SparCC significant (two-sided pseudo-P $<0.01,100$ bootstrapping random permutations) and correlations with a magnitude of SparCC $>0.6$ (positive correlation-blue edges) or SparCC $<-0.6$ (negative correlation-red edges) were included into the network plots. Each node represents an OTU, based on $H$ haI enzyme T-RFLP fingerprint. The size of each node is proportional to the number of connections (that is, degree), while the color of each node is represented by a gradient of betweenness centrality. Network graphs were built with 'Fruchterman Reingold' design, on Gephi software.

Fig. 4 Habitat microbial specialization across mesoregions. The $\mathrm{x}$ and $\mathrm{y}$ axes represent the OTUs abundance turnover between regions. The number and the percentage of generalists and specialists for each habitat comparison. The classification of generalists and specialists was performed through the CLAM test function in vegan R package, according to the estimated species relative abundance. The test was applied with arguments of $K=2 / 3$ and $P<0.005$, according to the supermajority rule. All the counts were added by 1 to let the marginal OTUs evenly arranged in the plot space.

Fig. 5 The distance-decay relationships among pairs of microbial communities, within neighborhoods from 0.03 to $378 \mathrm{~km}$, for (a) overall communities, (b) generalists and (c) specialists. The $\mathrm{x}$ axis represents the distance between pairwise microbial communities ( $\mathrm{n}=324$ samples; 13040 beta pairwise comparisons) and the y axis represents the BrayCurtis dissimilarity for each pair of microbial communities (black border circles). The red lines represent the fitted GLM exponential models, and the blue lines represent the fitted GLM power-law models. The slopes of distance-decay relationships are significantly higher than zero $(\mathrm{P}<0.05)$.

Fig. 6 Samples fitting to theoretical ecological models, based on Akaike information criterion (AIC) for rank abundance distributions of microbial OTUs, across land uses and seasons, in the subtropical Atlantic Forest Biome, Southern Brazil. (a) Rank abundance models based on corrected AIC value from Poisson distributions using maximum likelihood estimation. The lowest AIC value for each sample represented the best-fitted model for general community's assembly. Best-fitted models were calculated by the general equation AIC $=-2 \log$-likelihood $+2 \times$ npar. ZSM (Zero Sum Multinomial) and Broken-stick are null models regarding to theoretical neutral assembly while Preemption and Lognormal are niche-based models regarding to deterministic assembly. (b) Boxplots of distributions of calculated dispersal rates across land uses and seasons showing the median (thick black line), the first quartile (lower box bound), the third quartile (upper box bound) and the range of data values that deviate from the box (vertical black lines). Dispersal rates were compared through Kruskal-Wallis (chi-square) non-parametric test with Bonferroni correction. Uppercase letters represent differences between seasons for the same land use while lowercase letters represent differences among land uses for the same season $\left(\mathrm{P}_{\text {corrected }}<0.05\right)$. Dispersal rates were calculated by Etienne's formula. Values of dispersal are between 0 and 1, where the higher the value the greater the 
tendency to migration of members of a local microbial community, as represented by each of the 324 soil samples.

Fig. 7 Pairwise beta diversities distribution and simulated deviation from null expectation. Beta pairwise diversities at (a) local and (b) regional scales. Bar-plots of Bray-Curtis dissimilarities across land uses and seasons showing the mean and the standard deviation (vertical black lines) of observed (dark colors) and simulated (light colors) beta pairwise diversities (10000 simulations). Z-scores at (c) local and (d) regional scales. Box-plots of distributions across land uses and seasons showing the median (thick black line), the first quartile (lower box bound), the third quartile (upper box bound) and the range of data values that deviate from the box (vertical black lines). Horizontal lines separate lower and upper significance thresholds of $Z$-scores distributions $(Z=-2$ and +2 , respectively; $\mathrm{P}<0.05)$. Z-scores were generated under null model method 'swap_count' with 10000 simulations. $\mathrm{H}_{1}$ : observed beta diversity is less or greater than simulated values of beta diversity.

\section{TABLE LEGENDS}

Table 1 Overall topological properties of SparCC networks of co-occurrence between OTUs, following long-term land-use change and seasons.

\section{Footnote:}

${ }^{a}$ Microbial OTUs with at least one significant $(P<0.01)$ and strong $($ SparCC $>0.6$ or $<-$ $0.6)$ correlation;

${ }^{\mathrm{b}}$ Number of connections/correlations obtained by SparCC analysis;

${ }^{\mathrm{c}}$ SparCC positive correlation $(>0.6$ with $P<0.01)$;

${ }^{\mathrm{d}}$ SparCC negative correlation $(<-0.6$ with $P<0.01)$;

${ }^{\mathrm{e}}$ The capability of the nodes to form highly connected communities, that is, a structure with high density of between nodes connections (inferred by Gephi);

${ }^{\mathrm{f}} \mathrm{A}$ community is defined as a group of nodes densely connected internally (Gephi);

${ }^{\mathrm{g}}$ The longest distance between nodes in the network, measured in number of edges (Gephi);

${ }^{\mathrm{h}}$ Average network distance between all pair of nodes or the average length of all edges in the network (Gephi);

${ }^{\mathrm{i}}$ The average number of connections per node in the network, that is, the node connectivity (Gephi);

${ }^{\mathrm{j}}$ How nodes are embedded in their neighborhood and the degree to which they tend to cluster together (Gephi).

Table 2 Relative contribution of geographic distance, abiotic factors, and biotic factors influencing bacterial communities with different niche occupancies at overall, local, and regional scales. We calculated Pearson product-moment correlations from the simple (Mantel test; 1000 permutations; $P<0.05$ ) and the controlled effects (partial Mantel test; 1000 permutations; $P<0.05$ ). From a set of 64 measured parameters, only non-collinear and significant variables were forward-selected and used in the model. Local and regional microbial communities were selected by the geographic limit for autocorrelation (Moran's I $=97.196 \mathrm{~km} ; \mathrm{P}<0.05$ ).

Table 3 Individual factors influencing bacterial communities with different niche occupancies at overall, local, and regional scales. We calculated Pearson product-moment 
1501 correlations from the controlled effects ((partial Mantel test; 1000 permutations; $P<$ 1502 0.05). Only non-collinear and significant variables were forward-selected and used in the 1503 model. Local and regional microbial communities were selected by the geographic limit 1504 for autocorrelation (Moran's I $=97.196 \mathrm{~km}$; P < 0.05). 


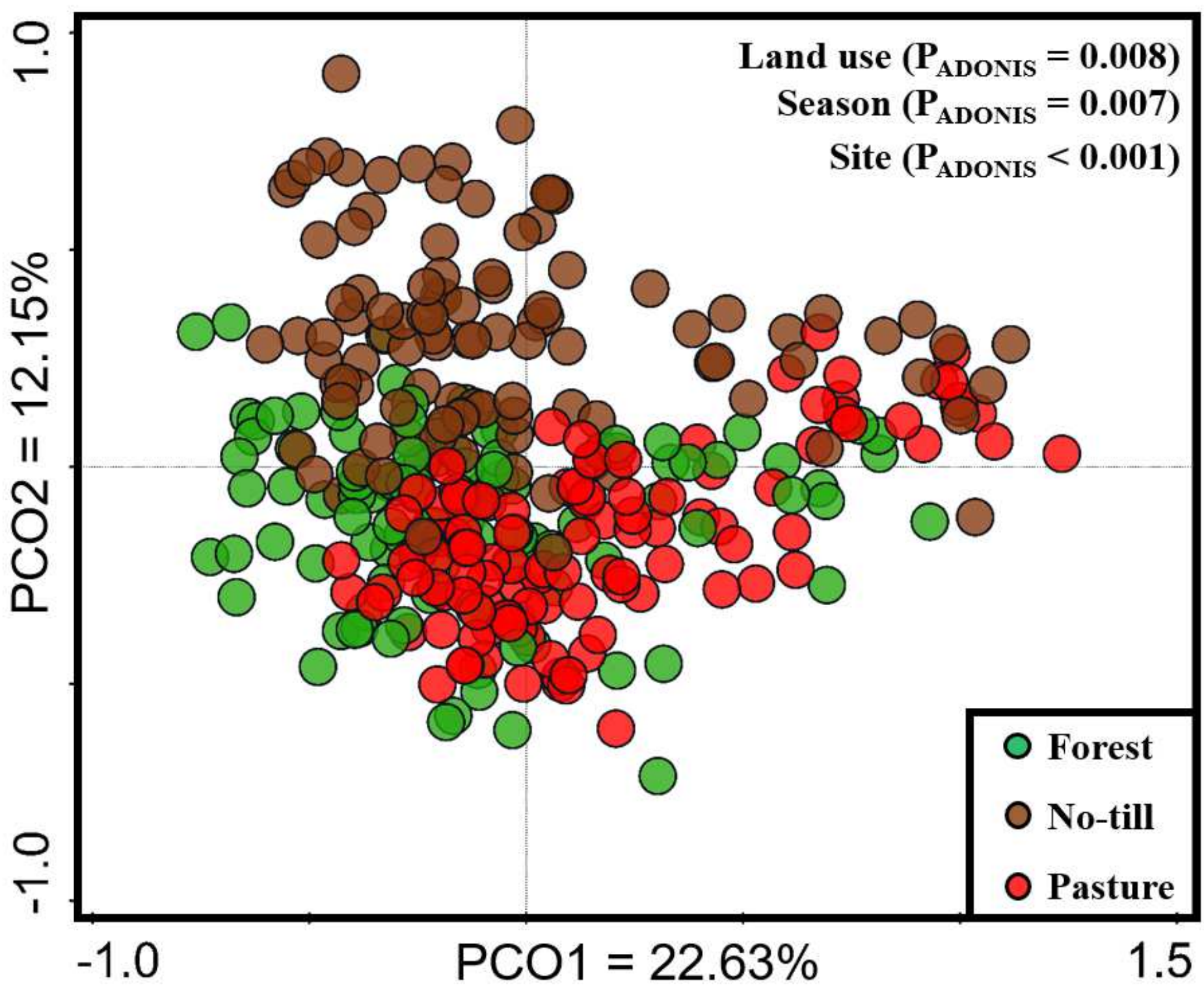

Figure 1

Principal Coordinates Analysis (PCoA) of soil microbial communities across land uses, in the subtropical Atlantic Forest Biome, Southern Brazil. Plots were generated using Bray-Curtis distance matrices with 1000 Monte-Carlo permutations. Samples are colored as follow: forest, green circles; no-till, brown circles; pasture, red circles; Differences in microbial beta diversities clustering among land-uses were evaluated through Adonis-PERMANOVA ( $n=324$ samples; 999 permutations; $P_{\text {ADONIS }}<0.05$ ). 

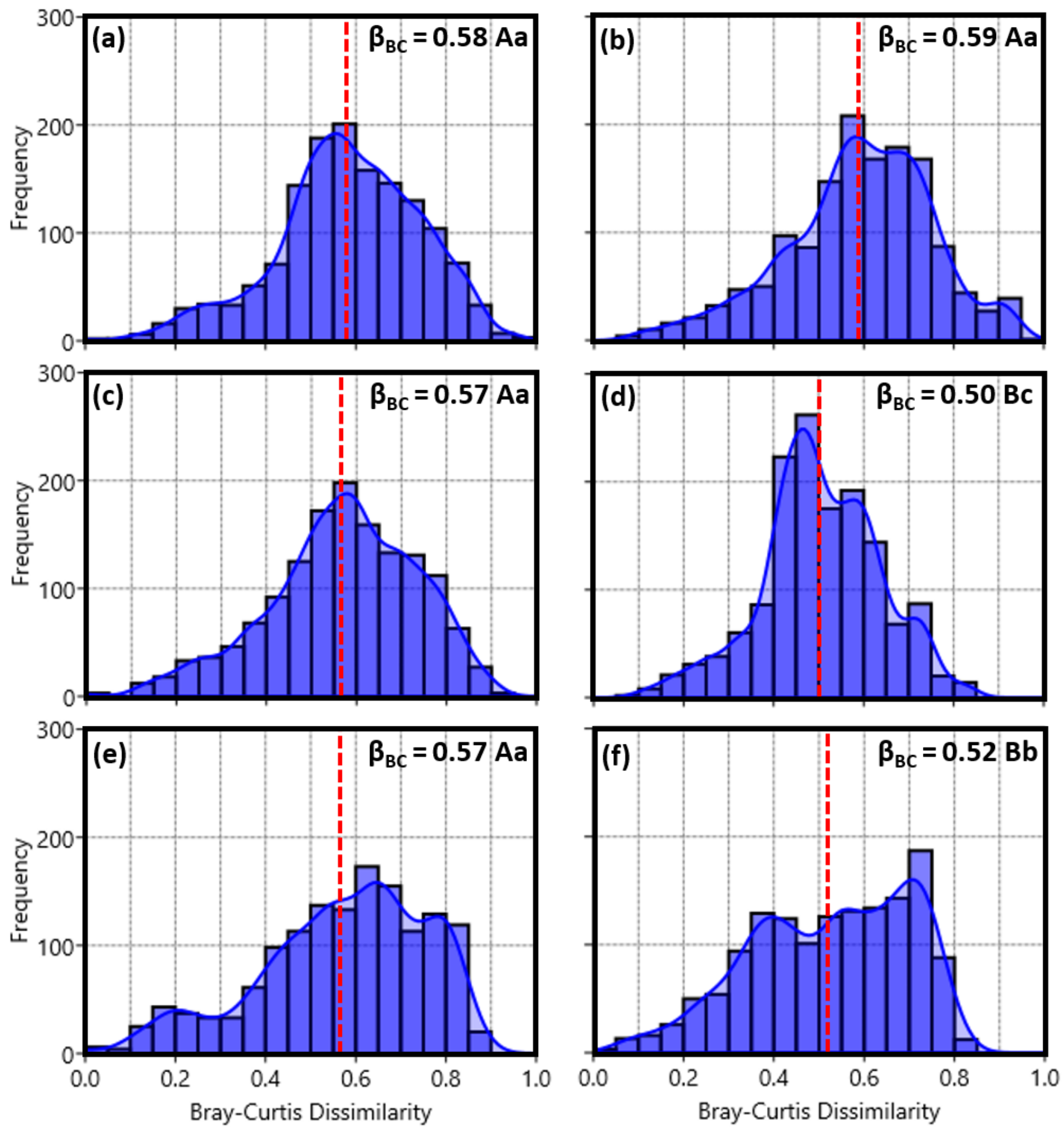

Figure 2

Beta diversity distributions between pairs of microbial communities across seasons and land uses, in the Brazilian Atlantic Rainforest Biome, Southern Brazil. (a) Forest winter; (b) Forest summer; (c) No-till winter; (d) No-till summer; (e) Pasture winter, and; (f) Pasture summer. Histograms show the distribution of observed pairwise Bray-Curtis dissimilarities ( $\mathrm{x}$ axis) and the frequency of pairwise beta diversities for each diversity rank bin (y axis). Probability Kernel densities are represented by the blue lines. Pairwise 
distributions were compared through Kruskal-Wallis (chi-square) non-parametric test with Bonferroni correction. Uppercase letters represent differences between seasons for the same land use while lowercase letters represent differences among land uses for the same season $\left(P_{\text {corrected }}<0.05\right)$. The red dashed lines represent the mean beta Bray-Curtis dissimilarity for each set of comparisons $(n=54$ samples; 1341 beta pairwise comparisons). $\beta_{\mathrm{BC}}$ Beta Bray-Curtis dissimilarity.
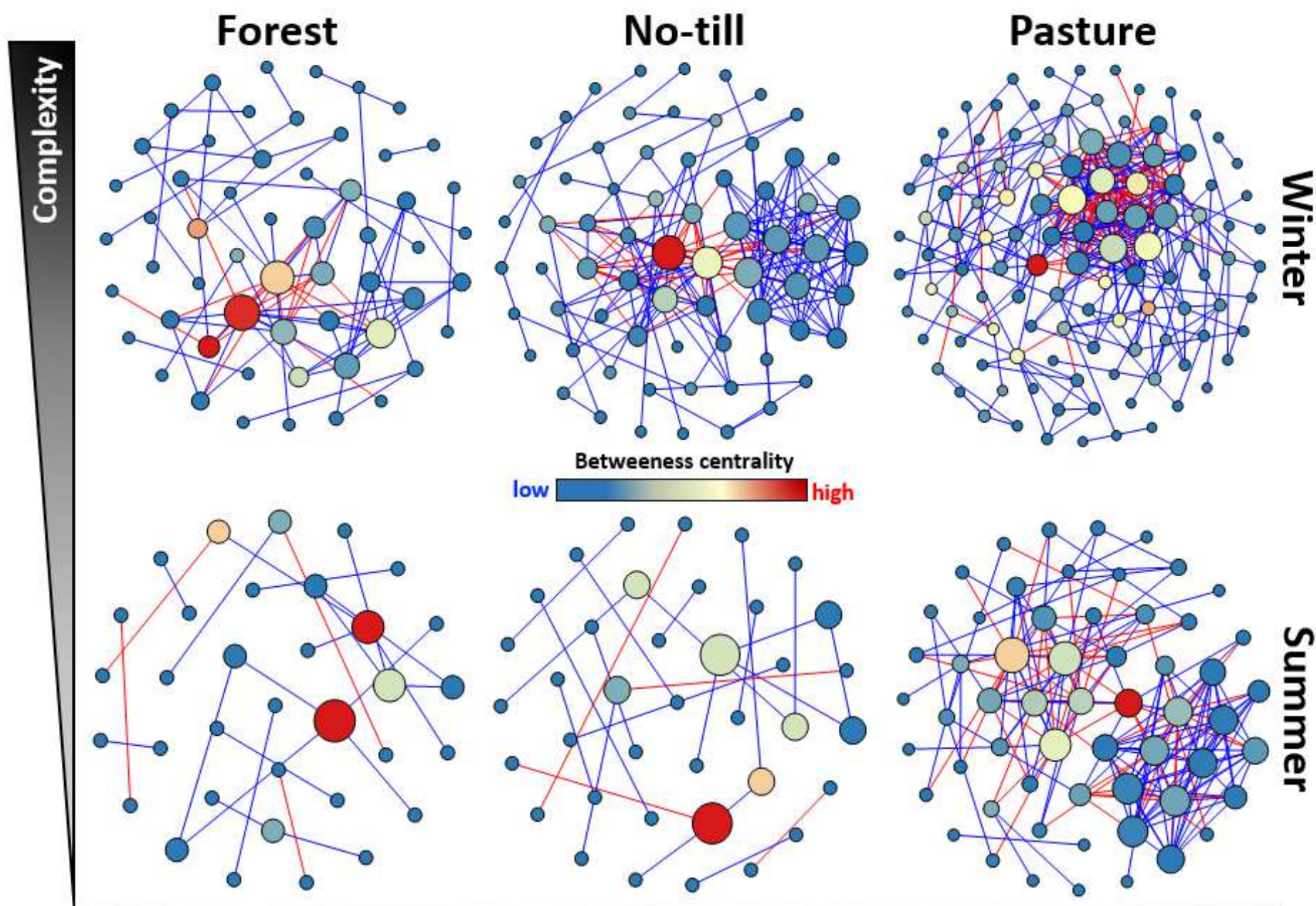

Complexity

\section{Figure 3}

Overall SparCC network plots of co-occurrence and co-exclusion between OTUs, following long-term land use change and seasons. Only OTUs with SparCC significant (two-sided pseudo-P $<0.01,100$ bootstrapping random permutations) and correlations with a magnitude of SparCC $>0.6$ (positive correlation-blue edges) or SparCC $<-0.6$ (negative correlation-red edges) were included into the network plots. Each node represents an OTU, based on Hhal enzyme T-RFLP fingerprint. The size of each node is proportional to the number of connections (that is, degree), while the color of each node is represented by a gradient of betweenness centrality. Network graphs were built with 'Fruchterman Reingold' design, on Gephi software. 


\section{Habitat Specialization}

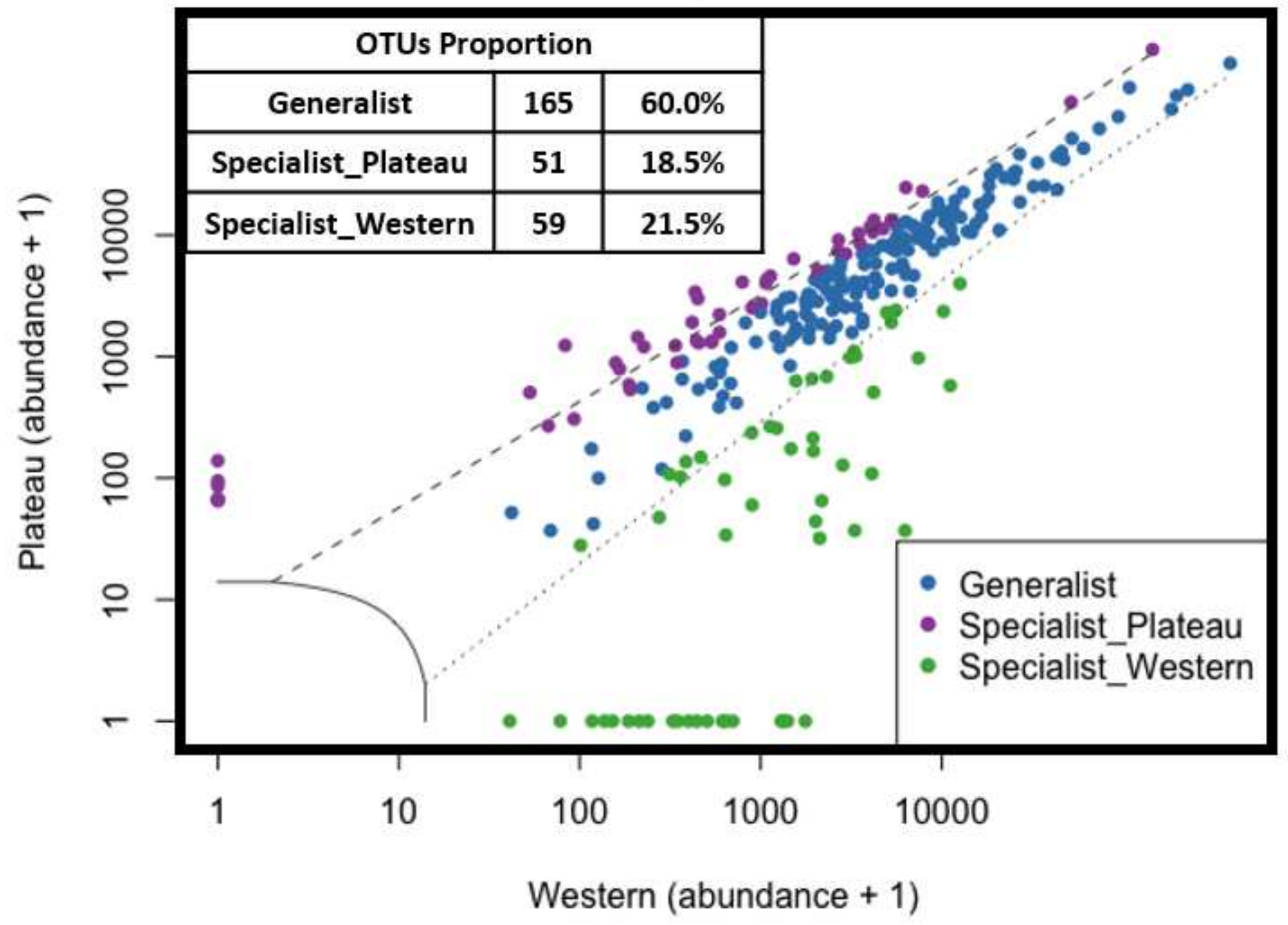

Figure 4

Habitat microbial specialization across mesoregions. The $\mathrm{x}$ and $\mathrm{y}$ axes represent the OTUs abundance turnover between regions. The number and the percentage of generalists and specialists for each habitat comparison. The classification of generalists and specialists was performed through the CLAM test function in vegan $\mathrm{R}$ package, according to the estimated species relative abundance. The test was applied with arguments of $K=2 / 3$ and $P<0.005$, according to the supermajority rule. All the counts were added by 1 to let the marginal OTUs evenly arranged in the plot space.

\section{Figure 5}

The distance-decay relationships among pairs of microbial communities, within neighborhoods from 0.03 to $378 \mathrm{~km}$, for (a) overall communities, (b) generalists and (c) specialists. The $x$ axis represents the distance between pairwise microbial communities ( $n=324$ samples; 13040 beta pairwise comparisons) 
and the $y$ axis represents the Bray-Curtis dissimilarity for each pair of microbial communities (black border circles). The red lines represent the fitted GLM exponential models, and the blue lines represent the fitted

GLM power-law models. The slopes of distance-decay relationships are significantly higher than zero $(\mathrm{P}<$ 0.05).

(a)

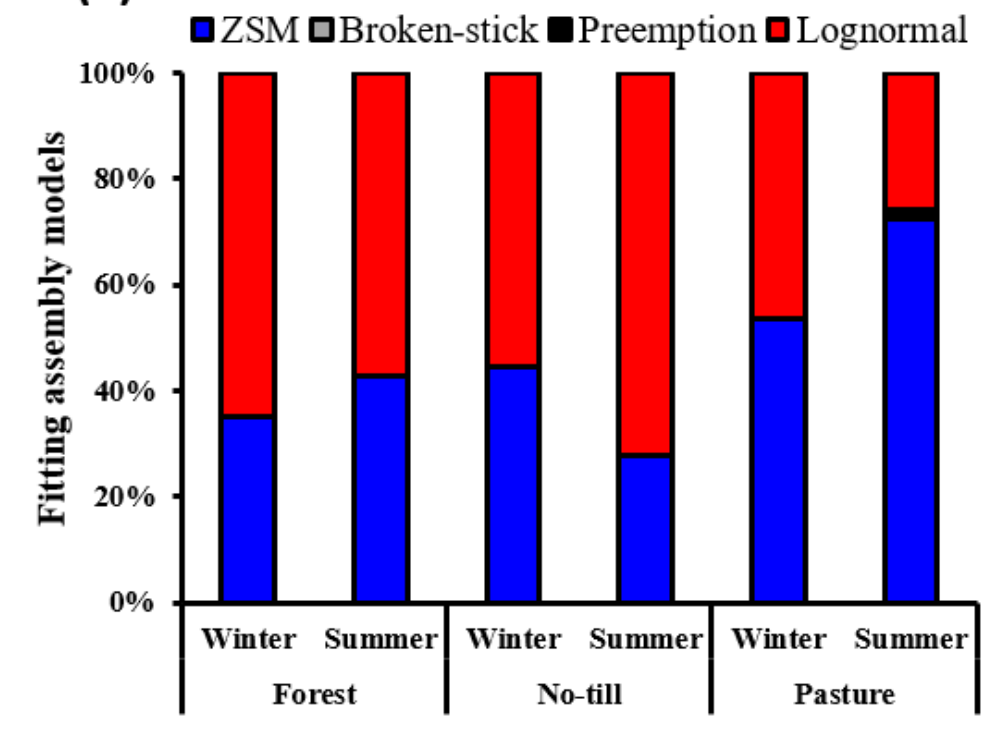

(b)

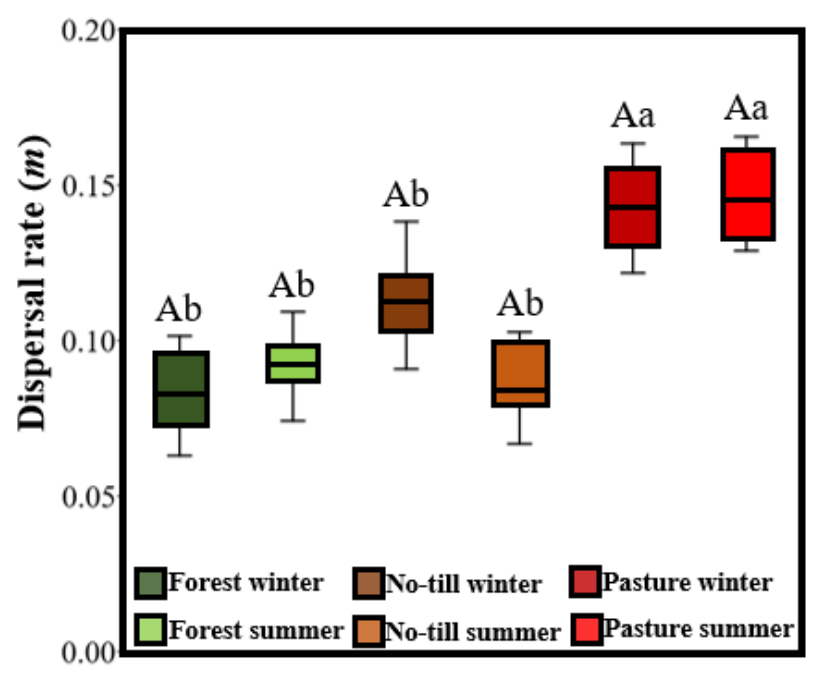

\section{Figure 6}

Samples fitting to theoretical ecological models, based on Akaike information criterion (AIC) for rank abundance distributions of microbial OTUs, across land uses and seasons, in the subtropical Atlantic Forest Biome, Southern Brazil. (a) Rank abundance models based on corrected AIC value from Poisson distributions using maximum likelihood estimation. The lowest AIC value for each sample represented the best-fitted model for general community's assembly. Best-fitted models were calculated by the general equation AIC $=-2$ log-likelihood $+2 \times$ npar. ZSM (Zero Sum Multinomial) and Broken-stick are null models regarding to theoretical neutral assembly while Preemption and Lognormal are niche-based models regarding to deterministic assembly. (b) Box plots of distributions of calculated dispersal rates across land uses and seasons showing the median (thick black line), the first quartile (lower box bound), the third quartile (upper box bound) and the range of data values that deviate from the box (vertical black lines). Dispersal rates were compared through Kruskal-Wallis (chi-square) non-parametric test with Bonferroni correction. Uppercase letters represent differences between seasons for the same land use while lowercase letters represent differences among land uses for the same season $\left(P_{\text {corrected }}<0.05\right)$. Dispersal rates were calculated by Etienne's formula. Values of dispersal are between 0 and 1 , where the higher the value the greater the tendency to migration of members of a local microbial community, as represented by each of the 324 soil samples. 


\section{Figure 7}

Pairwise beta diversities distribution and simulated deviation from null expectation. Beta pairwise diversities at (a) local and (b) regional scales. Bar-plots of Bray-Curtis dissimilarities across land uses and seasons showing the mean and the standard deviation (vertical black lines) of observed (dark colors) and simulated (light colors) beta pairwise diversities (10000 simulations). Z-scores at (c) local and (d) regional scales. Box-plots of distributions across land uses and seasons showing the median (thick black line), the first quartile (lower box bound), the third quartile (upper box bound) and the range of data values that deviate from the box (vertical black lines). Horizontal lines separate lower and upper significance thresholds of $Z$-scores distributions $(Z=-2$ and +2 , respectively; $P<0.05)$. $Z$-scores were generated under null model method 'swap_count' with 10000 simulations. $\mathrm{H}_{1}$ : observed beta diversity is less or greater than simulated values of beta diversity.

\section{Supplementary Files}

This is a list of supplementary files associated with this preprint. Click to download.

- GossSouzaetalsupporting2022v0.pdf 